\title{
The ocean-atmosphere response to wind-induced thermocline changes in the tropical South Western Indian Ocean
}

\author{
Iris Manola $\cdot$ F. M. Selten • W. P. M. de Ruijter • \\ W. Hazeleger
}

Received: 13 May 2014 / Accepted: 10 September 2014 / Published online: 10 October 2014

(c) The Author(s) 2014. This article is published with open access at Springerlink.com

\begin{abstract}
In the Indian Ocean basin the sea surface temperatures (SSTs) are most sensitive to changes in the oceanic depth of the thermocline in the region of the Seychelles Dome. Observational studies have suggested that the strong SST variations in this region influence the atmospheric evolution around the basin, while its impact could extend far into the Pacific and the extra-tropics. Here we study the adjustments of the coupled atmosphere-ocean system to a winter shallow doming event using dedicated ensemble simulations with the state-of-the-art EC-Earth climate model. The doming creates an equatorial Kelvin wave and a pair of westward moving Rossby waves, leading to higher SST 1-2 months later in the Western equatorial Indian Ocean. Atmospheric convection is strengthened and the Walker circulation responds with reduced convection over Indonesia and cooling of the SST in that region. The Pacific warm pool convection shifts eastward and an oceanic Kelvin wave is triggered at thermocline depth. The wave leads to an SST warming in the East Equatorial Pacific 5-6 months after the initiation of the Seychelles Dome event. The atmosphere responds to this warming with weak anomalous atmospheric convection. The changes in the upper tropospheric divergence in this sequence of events create large-scale Rossby waves that propagate away from the tropics along the atmospheric waveguides. We suggest to repeat these types of experiments with other models to test the robustness of the results. We also suggest to create the doming event in June so that the East-Pacific warming occurs in November when the atmosphere is most sensitive
\end{abstract}

I. Manola $(\bowtie) \cdot$ F. M. Selten · W. P. M. de Ruijter · W. Hazeleger Global Climate Department, Royal Netherlands Meteorological Institute, POBox 201, 3730 AE De Bilt, The Netherlands e-mail: manola@knmi.nl to SST anomalies and El Niño could possibly be triggered by the doming event under suitable conditions.

Keywords Seychelles Dome - Thermocline changes · Air-sea interactions

\section{Introduction}

Oceanic regions with a shallow thermocline play a key role in the air-sea interaction. A shallow thermocline and a shallow mixed layer are sensitive to changes in the local wind stress, enhancing or suppressing the upwelling of cold waters from below leading to strong SST anomalies (Duvel et al. 2004). It provides a window for interaction between ocean and atmosphere as the tropical atmosphere is sensitive to SST changes and thermocline disturbances are easily created by windstress anomalies. Effects of this interaction can be remotely felt as atmospheric and oceanic waves move away from the region. A shallow thermocline region is found in the Western Indian Ocean (IO), along a narrow region just south of the equator, referred to as the Seychelles Dome (SD, Yokoi et al. 2008). The SD is characterized by a shallow thermocline that experiences large seasonal to interannual variability and strong seasonal upwelling. Generally, the Indian Ocean (IO) is known to exhibit a large impact on climate variability (Hoerling et al. 2004; Schott et al. 2009; Luffman et al. 2009; Yang et al. 2009). More specifically, a lot of attention has been devoted recently to the SD region, as it is the region where the SSTs are most sensitive to changes of the thermocline and that in turn can influence the climate system around the Indian Ocean and possibly beyond.

Previous studies have documented the impact of the SD region on precipitation over Eastern Africa (Goddard and 
Graham 1999) and Asia (Vecchi and Harrison 2004). The SD region has been mentioned as a possible predictor for the Indian Monsoon season (Izumo and Boyer 2008), as it influences the timing of its initiation (Annamalai et al. 2005a). In addition SD variability affects IO cyclogenesis for several reasons. First, the SST variations in the SD region are large and impact the atmospheric stability and second, the SD thermocline is most shallow between December and June which coincides with the South-Western Indian Ocean cyclone season (Xie et al. 2002; Hermes and Reason 2008). Finally, changes in the SD area may also impact the Madden Julian Oscillation (MJO) (Vialard et al. 2008, 2009; Schott et al. 2009; Jayakumar and Gnanaseelan 2012).

The shallow thermocline is maintained by both local and remote forcings (Yokoi et al. 2008; Hermes and Reason 2008; Tozuka et al. 2010; Lloyd and Vecchi 2010; Jayakumar et al. 2011; Trenary and Han 2012). Locally, variations in the upwelling through Ekman pumping are due to variations in the wind stress curl in the convergence region of the south-easterly trade winds and the north-westerly monsoonal winds (Murtugudde and Busalacchi 1999; Hermes and Reason 2008; Trenary and Han 2012). Remotely, the doming region is influenced by the arrival of upwelling or downwelling Rossby waves that emanate from the Eastern IO and are forced by wind stress curl in the Pacific ocean (Rao and Behera 2005). It is suggested that the remote Rossby wave forcing mostly attributes to the doming between January and July, while for the remainder local wind stress forcing is dominant (Trenary and Han 2012). The Indonesian Throughflow (ITF) can also play a role in the forcing of the SD (Zhou et al. 2008). It is noted that a shallower Dome can be expected in case of a ITF shut down (Yokoi et al. 2008).

The SD variations co-vary with both the Indian Ocean Dipole (IOD) and the El Niño-Southern Oscillation (ENSO) (Jochum and Murtugudde 2005; Annamalai et al. 2005b, 2007; Tozuka et al. 2010; Trenary and Han 2012). The relation with the IOD explains why shallow SD events are more pronounced in boreal winter. During an IOD or an ENSO event the associated wind stress anomalies in the eastern IO lead to local Ekman pumping and excite a westward propagating Rossby wave (Xie et al. 2002; Chowdary et al. 2009). In case of a negative IOD or a La Niña event the Rossby wave is upwelling and strengthens the shallowing of the thermocline over the SD area.

The doming region is easily identified as a region with minimum depth of the 20 degrees isotherm (D20, Fig. 1a). D20 is an appropriate level to study the distribution of the ocean thermocline in the tropics. Within the IO basin the region where the thermocline is shallowest due to strongest mean upwelling is the SD area (marked by the black rectangle). This is also the region of strongest coupling between thermocline depth variations and SST as witnessed by the high correlation between monthly anomalies of D20 and local SSTs (Fig. 1b, see also Xie et al. 2002 and Annamalai et al. 2005a). This strong thermocline-SST connection, in combination with the SD region being close to the equator, where the atmosphere is sensitive to SST changes, indicates that the SD region is potentially a key region for ocean-atmosphere interaction in the IO and variations in the tropical circulation.

In order to determine the season in which shallow events with strong impacts on the coupled system occur most likely, we assessed the mean seasonal cycle of the depth of the SD thermocline, as well as the mean seasonal cycle of interannual SST variability. We define the Seychelles Dome Index (SDI) as the depth of the 20 degrees isotherm averaged over the area $50^{\circ} \mathrm{E}-80^{\circ} \mathrm{E}$ and $5^{\circ} \mathrm{S}-10^{\circ} \mathrm{S}$ and its seasonal cycle is plotted in Fig. 1c. The biennial character of the SDI is apparent, as has been noted previously by Hermes and Reason (2008), Yokoi et al. (2008) and Tozuka et al. (2010), with a first minimum in January, a second in June and maxima in spring and autumn. It should be noted that the exact boundaries of the SD region slightly vary in the different studies, without significant influence in the seasonal cycle. The standard deviation of the SDI is quite large year-round (indicated by the shaded area), with a maximum in January. The seasonal cycle of the interannual variations in the area averaged monthly SST anomalies over the Dome region (Fig. 1d) also has a biennial character that is linked to the doming, with largest variations taking place in January and a secondary maximum in June.

The literature studies so far concentrate predominantly on the variability of the SD and on the phenomena determining this variability. There has been some effort to investigate how variations in the SD region feed back on the atmosphere and ocean (Xie et al. 2002; Annamalai et al. 2005a; Lloyd and Vecchi 2010; Swapna et al. 2013) but a complete study about the effects of a shallow SD thermocline event on the coupled system locally and remotely is still lacking.

Here we investigate the local and remote response of the coupled ocean-atmosphere system to shallow SD events that are created by prescribed wind stress anomalies over the South-Western IO with the use of ensemble simulations with the state-of-the-art coupled model EC-Earth (Hazeleger et al. 2012). We will investigate January events as climatologically the thermocline is shallow and both the SDI and the SSTs have maximum interannual variability in that month.

The content of the present study is organized as follows. We start with a description of the coupled model in Sect. 2. The seasonality of the Seychelles Dome region is analyzed in a 40 year control simulation with EC-Earth and compared with observations. Next, in Sect. 3 the experiment is 


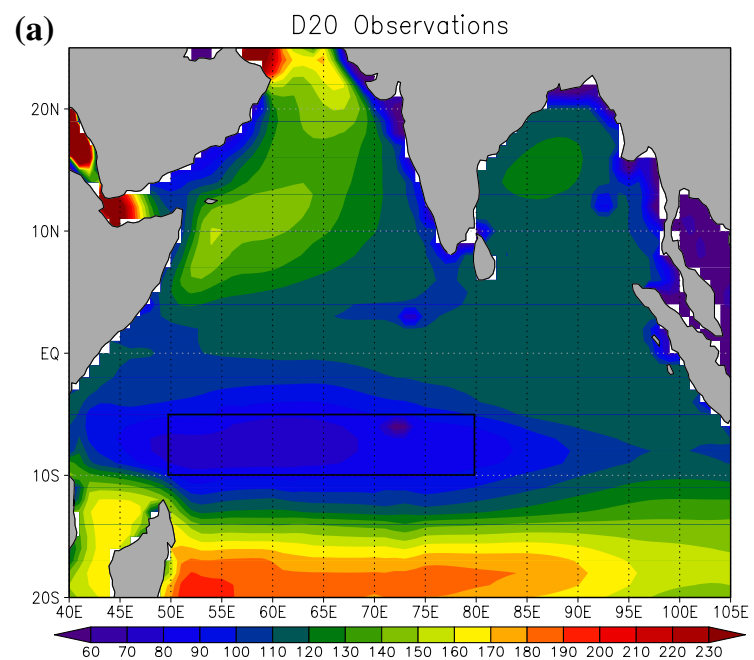

(c)

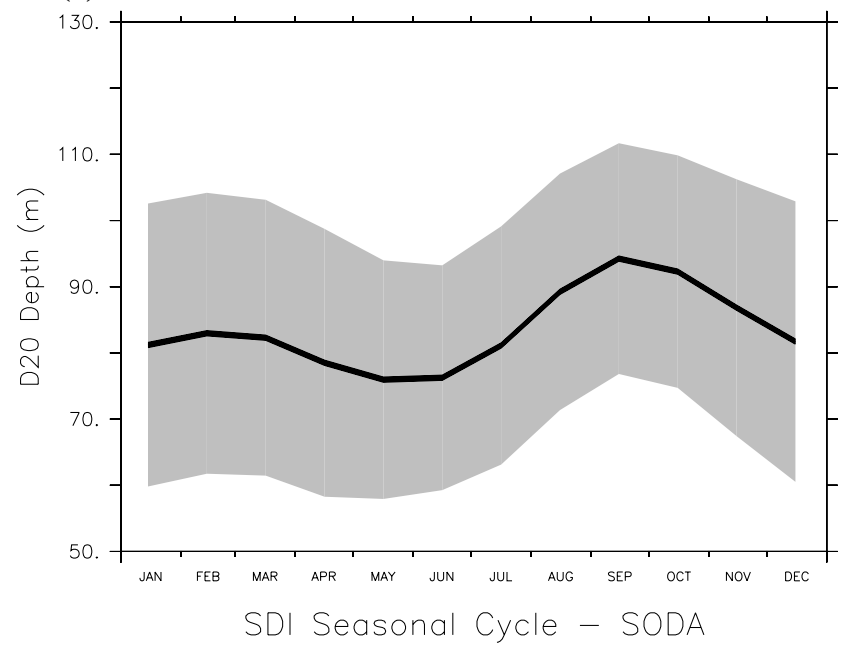

Fig. 1 Observations of the depth of the $20{ }^{\circ} \mathrm{C}$ isotherm (D20) from SODA reanalysis and of the SSTs from HadISST for the years 1979-2008. a The averaged depth of the $20^{\circ} \mathrm{C}$ isotherm. The depth is measured in meters. b The point to point correlations of the depth of monthly D20 anomalies with SST anomalies during the same years. The data are detrended. The black rectangular box indicates the Sey-

described. From the control run extreme shallow doming events are selected to define the wind stress forcing for the ensemble experiment. In Sect. 4 the response of the coupled system to a shallow SD doming event in January is described and discussed. The final section discusses the main results of this study.

\section{Data and model}

For the D20 analysis in Fig. 1 we used reanalysis data from the Simple Ocean Data Assimilation (SODA) version 2.1.6 for the years 1979-2008 (Carton and Giese 2008). For the same years we used SSTs from observations compiled in (b)

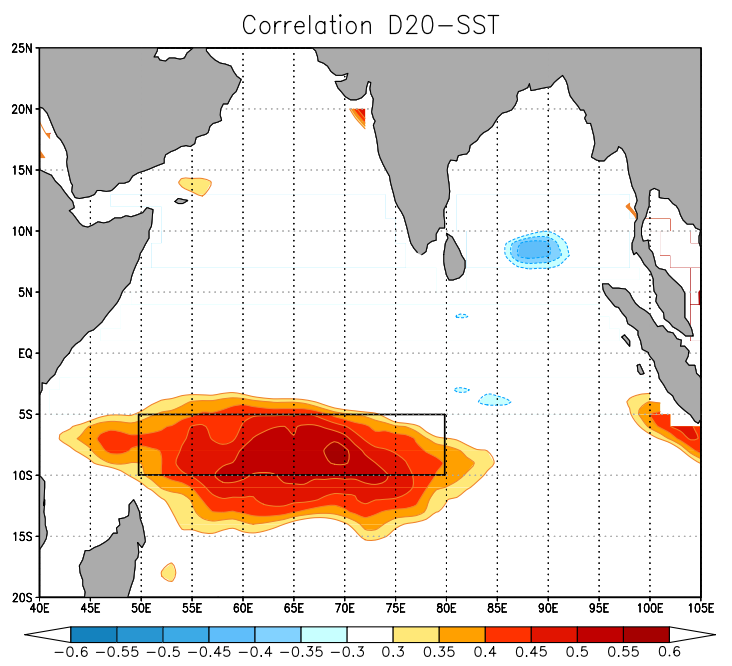

(d)

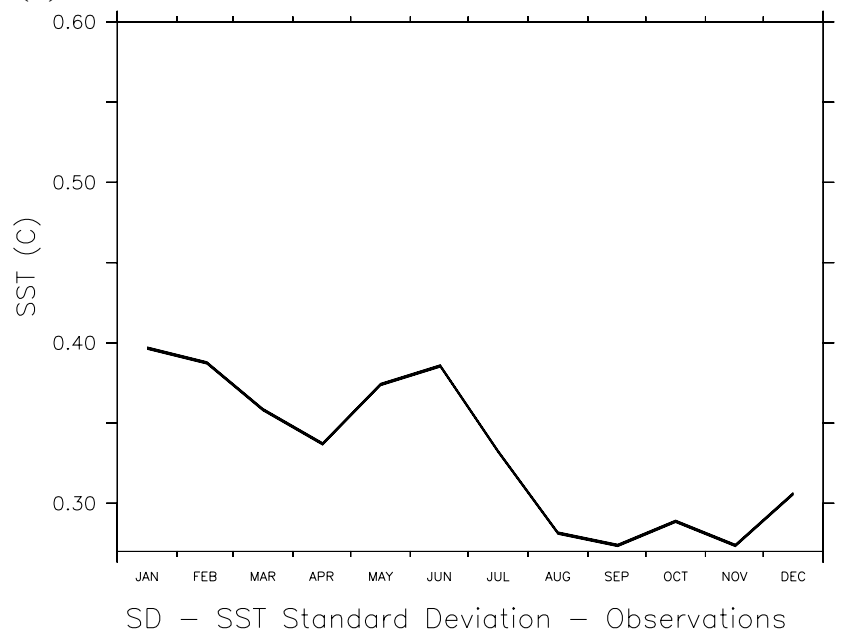

chelles Dome region. c The seasonal cycle of the SDI index for the 29 years of the SODA reanalysis. The gray shaded area represents one standard deviation of the interannual variations. The SDI index is the D20 anomaly averaged over the SD region expressed in meters. d The standard deviation of interannual monthly mean SST anomalies for each month of the year. The units are in ${ }^{\circ} \mathrm{C}$

the Hadley Center Sea Ice and Sea Surface Temperature data set (HadISST) (Rayner et al. 2002). For the analysis of the wind stress curl in Sect. 3, we used data from MERRA (NASA's Modern Era Retrospective-analysis for Research and Applications, Rienecker et al. 2011) for the years 1979-2011.

The model used in this study is the fully coupled ECEarth global climate model (Hazeleger et al. 2012). ECEarth is based on the Integrated Forecast System (IFS) of the European Center of Medium Range Weather Forecast (ECMWF). It consists of the IFS atmospheric general circulation model coupled to the ocean general circulation model NEMO, a sea-ice model and a land model. The atmospheric component has a spectral resolution of T159, 
(a)

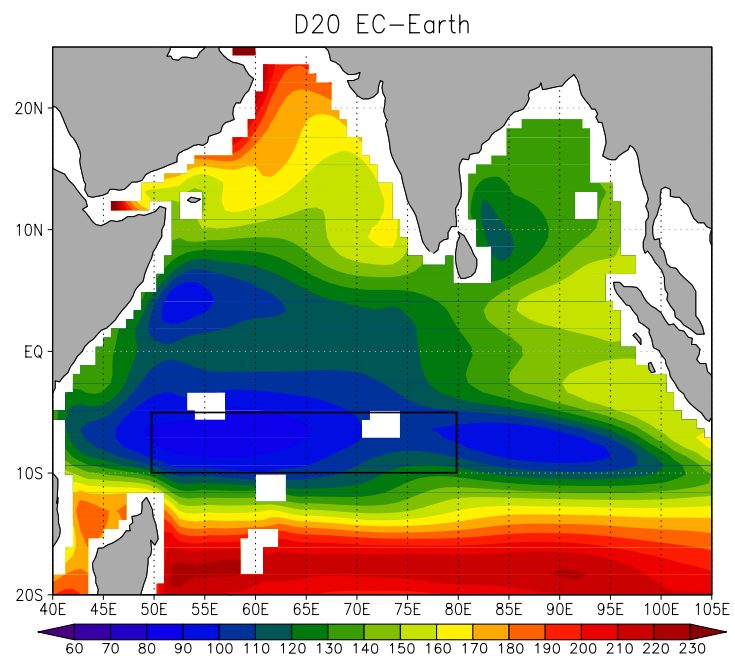

(c)

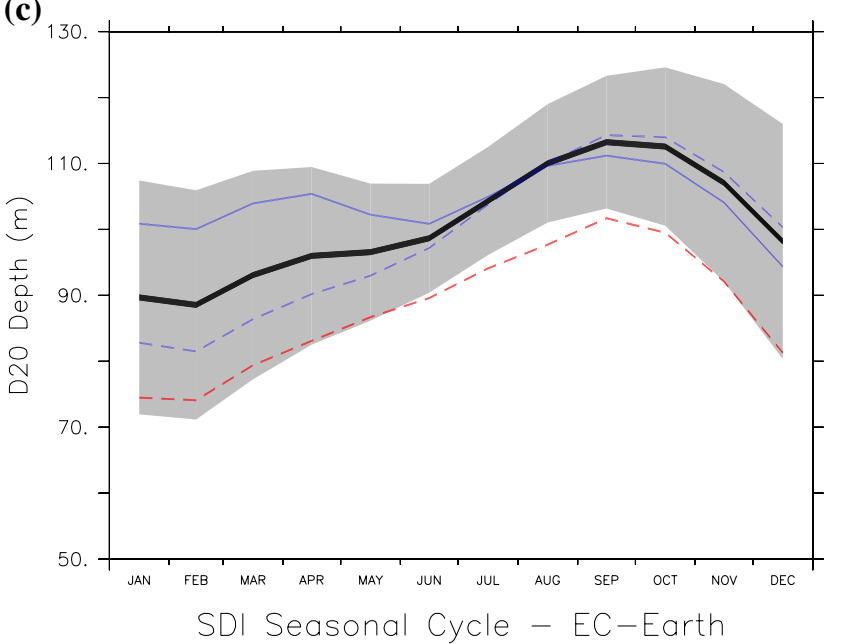

Fig. 2 Same as in Fig. 1, but for EC-Earth data from the 40 years control run. a The depth of the $20^{\circ} \mathrm{C}$ isotherm averaged over the 40 simulation years. The depth is measured in meters. b The point to point correlations of monthly D20 depth anomalies with SST anomalies in the 40 simulation years. The data are detrended. The black rectangular box indicates the Seychelles Dome region. c The black line represents the seasonal cycle of the SDI index. The gray shaded area is one standard deviation of the interannual variations. The SDI index

corresponding approximately to $1.125 \times 1.125$ degree horizontal resolution and the ocean resolution is $1 \times 1$ degree with a refined resolution near the equator.

In order to evaluate the IO variability simulated by ECEarth we used a 40 years control simulation and compared the results with the observations. The model was equilibrated under constant 1850 external forcings. Next it was integrated from 1850 to 2000 under historical forcings and subsequently for another 88 years under constant year 2000 forcings (solar radiation, aerosols, greenhouse gases and land use). Then it run for another 88 years under constant year 2000 forcing (solar radiation, aerosol, greenhouse gases and land use). In this study we use the last 40 years (b)

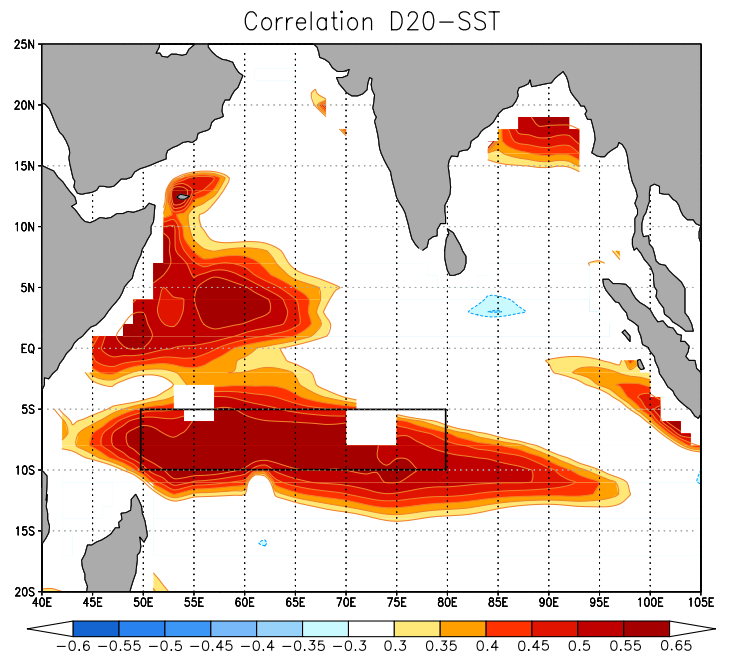

(d)

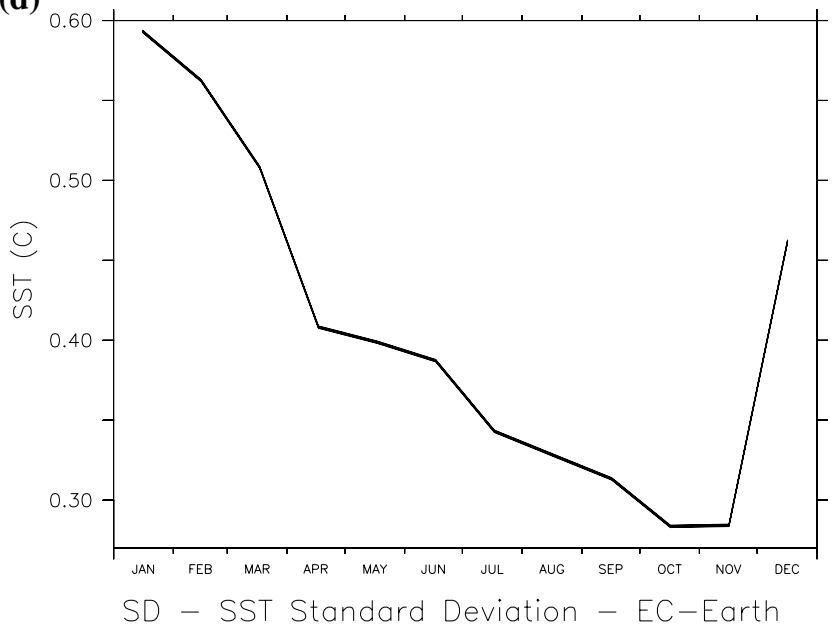

is the D20 anomaly averaged over the SD region expressed in meters. The red dashed line represents the averaged SDI seasonal cycle of the composite of the 5 most shallow SD years. The blue dashed line is the composite of the years with an annual-like seasonal cycle ( 25 years) and the solid blue line is the composite of years with an biennial-like seasonal cycle (15 years). d The standard deviation of interannual monthly mean SST anomalies for each month of the year. The units are in ${ }^{\circ} \mathrm{C}$

of this simulation. Similar graphs as in Fig. 1 are presented for EC-Earth in Fig. 2. Overall the depth of the thermocline as indicated by D20 in EC-Earth is about $10-20 \mathrm{~m}$ deeper compared to the SODA reanalysis, but the general structure is rather well simulated. In the SD region the thermocline is shallowest and the upwelling is strongest, in both model and reanalysis data. The model and the observations agree that the correlations between D20 and SST variations are maximum over the SD area. In addition, in the model the thermocline perturbations over the Western equatorial IO affect the SSTs more strongly as compared to the observations. We did not analyze the origin of this discrepancy, but possible reasons are differences in simulated wind stress 
anomalies, in the ocean response to wind stress anomalies and in the vertical mixing. The SDI in the model is about 10 meters too deep compared to the reanalysis, but overall the simulation has the major characteristics. In both model and reanalysis the Dome region is shallowest and most variable in winter and deepest in autumn. In the reanalysis a more pronounced biennial cycle is observed. To lay out this discrepancy, the data are separated in years where the behavior of the SDI is annual-like and in years where is bienniallike. Both cases were found in both model and reanalysis. In particular, in the model the $38 \%$ of the years show a biennial character, that increases to $74 \%$ for the reanalysis. These composites of the annual and biennial SDI cycles for the model are plotted in Fig. 2c. Both decadal variations of the Dome region and observational uncertainties contribute to the discrepancies in the seasonal cycle of the SDI, but these contributions are hard to quantify. Similar remarks also apply to the SST variations.

\section{Experimental set-up}

\subsection{The method}

To study the effect of a shallow doming two ensembles of 26-months long simulations are conducted. The initial conditions are obtained from the control run. Both ensembles are initialized at the 1 st of November from a year in the control simulation with a neutral SD thermocline and neutral ENSO conditions in the Pacific in the following January. For the ENSO evaluation we use the Nino 3.4 index (the averaged SST anomaly over $170^{\circ} \mathrm{W}-120^{\circ} \mathrm{W}$ and $5^{\circ} S-5^{\circ} \mathrm{N}$ ). The 40 ensemble members in the unforced run differ only in stochastic perturbations to the temperature field during the first day of the simulation.

In a second ensemble the wind stress that the ocean receives from the atmosphere is replaced by a prescribed windstress forcing over the SD region in the first two months that raises the thermocline in order to force a shallow Seychelles doming event in January. In all other aspects the conditions in the forced ensemble are the same as in the unforced ensemble. Statistical significant differences between the ensemble mean fields of both ensembles can be attributed to the action of the prescribed windstress in the SD region and analysing these differences as a function of time allows us to study the response of the coupled system to a shallow Seychelles doming event in January.

\subsection{Initial conditions and forcing}

The imposed forcing is the composite wind stress of the November and December months preceding the 5 January months with the shallowest SD thermocline in the 40 year control run. The seasonal cycle of the SDI composite for these shallowest SD years is depicted in Fig. 2c by the red dashed line. The composite of the extremes follows the climatological seasonal cycle of the SDI but is about one standard deviation shallower than the mean. The composite anomalous windstress curl for December (one month before the shallow Januaries) for the entire basin is shown in Fig. 3a. The area where the windstress is prescribed in the forced ensemble is marked by the inner rectangle. A linear transition region between the actual and the prescribed wind stress extends $2.5^{\circ}$ on each side and is marked in the figure by the outer rectangle.

The anomalous cyclonic curl over the SD region causes an Ekman upwelling that raises the thermocline locally in our experiment. North of the SD region an anticyclonic curl is present. This is a reflection of the general anticorrelation between windstress curl anomalies in December in the SD region and regions to the north (Fig. 3b). A similar anti-correlation is found in reanalysis data, as seen in Fig. 3c, where 33 Decembers from MERRA for the years 1979-2011 are used. Thus, when the thermocline in the SD region is raised by the windstress curl anomaly, to the north of the region the thermocline is depressed by the windstress curl anomaly. In the current experiment, part of the anticyclonic curl is included in the forcing as it is a part of the transition region between the prescribed and the actual wind stress. This will result in a forced downwelling of the thermocline locally north of the Seychelles dome region, an aspect that will be further discussed in the next section.

The amplitude of the prescribed wind stress anomaly in the forced ensemble was enhanced in order to simulate a strong rising of the Seychelles Dome, motivated by the fact that remote forcing by ocean dynamics, that contribute to the thermocline anomalies in the SD region in nature and in the control integration, are not taken into account. The composite for November is similar (not shown).

\section{Simulation results}

A graphic representation of the outcome from all runs of both ensembles is shown in Fig. 4. Here the evolution of the SDI for the 26 simulation months is plotted for each member of both ensembles (thin lines) and for the ensemble mean (thick line). The shallowing of the thermocline is clearly present in the forced ensemble during the first few months and the thermocline relaxes back to climatology in the months that follow. The description and interpretation of the temporal adjustment of the coupled system is discussed below for the forced phase (first two months) and the unforced phase of the simulation separately. We start with the forced phase. 


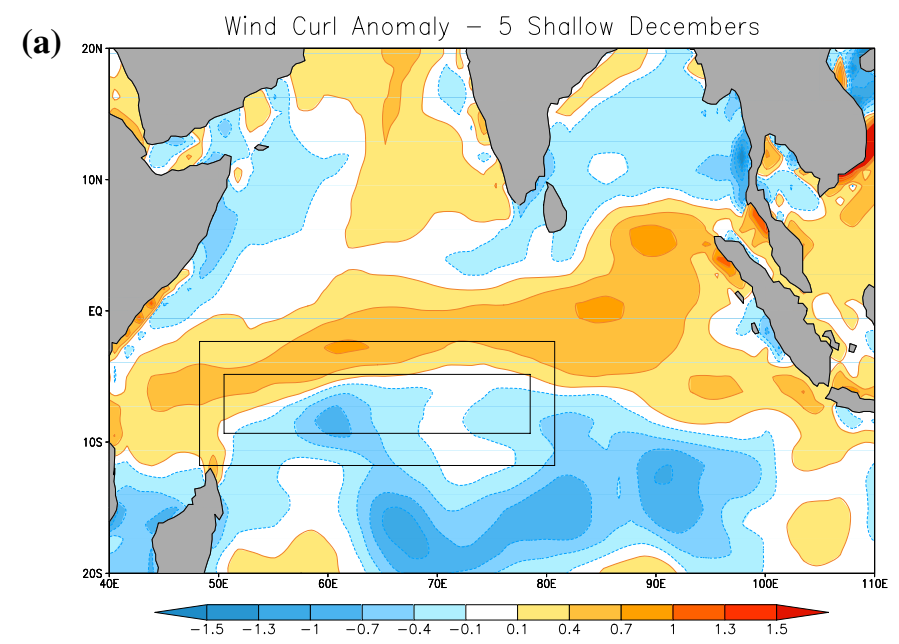

(b)

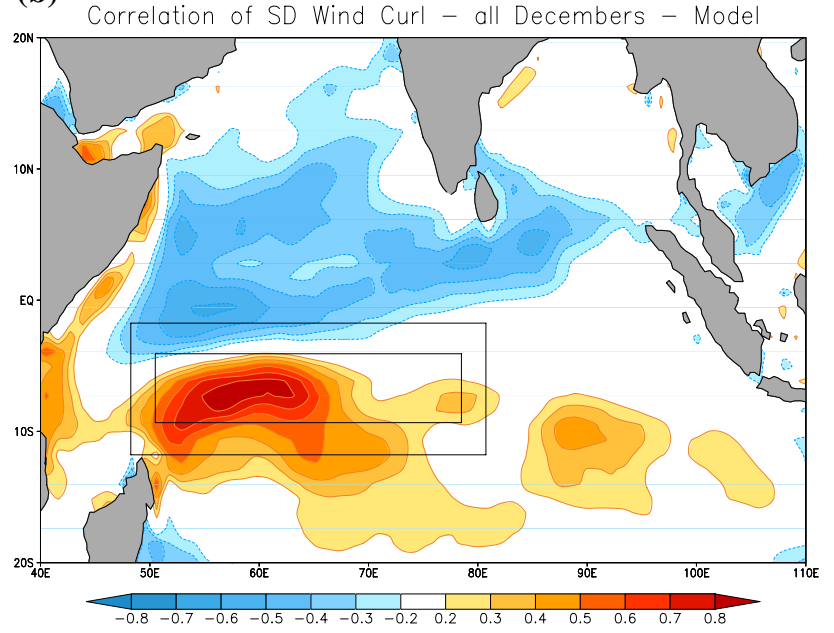

Fig. 3 a Composite of the anomalous wind stress curl for the month of December preceding the 5 January months in the control integration with shallowest SDI. The region where we prescribe this windstress anomaly in the forced ensemble is outlined by the inner black rectangle, between $50^{\circ} \mathrm{E}-80^{\circ} \mathrm{E}, 5^{\circ} \mathrm{S}-10^{\circ} \mathrm{S}$. The transition region between the prescribed and actual windstress field in the forced

\subsection{Forced phase-first two months}

This section describes the oceanic and atmospheric response to the imposed anomalous wind stress during November and December. During these two months the anomalous wind stress is applied over the SD region and the response is still limited to the IO basin. We start with the changes in the vertical ocean velocities due to Ekman upwelling and downwelling and continue with the SST and thermocline anomalies and their oceanic consequences. Finally we show how the atmosphere is influenced through changes in the SST.

Climatologically in boreal winter, oceanic upwelling takes place at the latitudes of the Dome and around the (c)

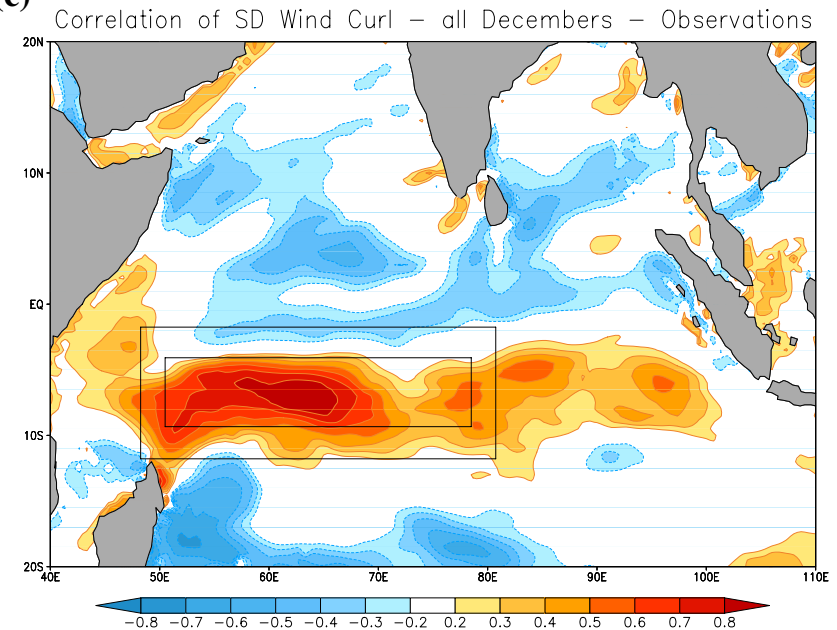

ensemble is indicated by the outer rectangle. Units are $10^{-7} \mathrm{Nm}^{-3}$. b Correlation coefficients between local anomalous wind stress curl anomalies and the area-averaged anomalous wind stress curl over the $\mathrm{SD}$ region in the 40 year control run for the month of December. c Same as in (b) for 33 Decembers from MERRA reanalysis data

equator. The upwelling is part of two wind-driven cells, with two downwelling regions just north of the SD and north of the equator. The changes in the cells in response to the prescribed wind stress are depicted in Fig. 5b, where the change in the vertical velocity $W$ is plotted averaged over the longitudes of the Dome $55^{\circ} \mathrm{E}-65^{\circ} \mathrm{E}$. The strong cyclonic curl over the Dome (Fig. 5a) drives an intense local Ekman upwelling that enhances the climatological regional upwelling. Just to north, around $3-4^{\circ} S$, the prescribed anticyclonic windstress curl drives the opposite Ekman motion, a downwelling, also enhancing the regional climatology. The southern wind-driven cell is strengthened and the northern cell responds with a moderate enhanced upwelling over the equator and a stronger downwelling around $3-4^{\circ} \mathrm{N}$. 
(a)

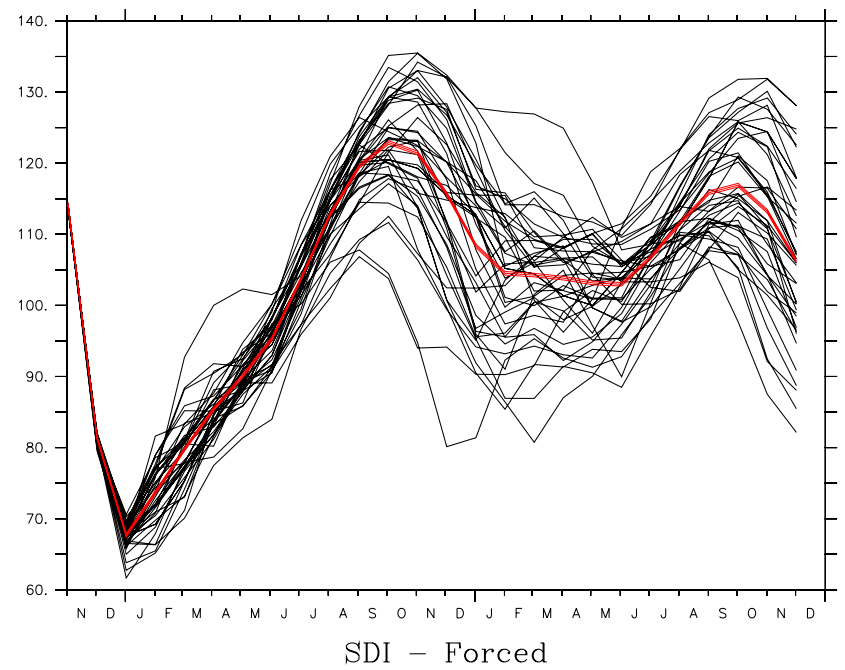

Fig. 4 The evolution of the SDI for the 26 simulation months for each member of $\mathbf{a}$ the forced ensemble and $\mathbf{b}$ the unforced ensemble. Thick red lines indicate the respective ensemble means. The only

Due to the upwelling, colder water is brought from below into the mixed layer, cooling the upper ocean and eventually the SSTs as well. The downwelling results in the opposite temperature adjustments (Fig. $5 \mathrm{~d}$ ).

The depression of the thermocline at $3-4^{\circ} \mathrm{S}$ and $3-4^{\circ} \mathrm{N}$ sets off in November as a pair of westward propagating downwelling Rossby waves and in addition an eastward propagating downwelling Kelvin wave along the equator is triggered (Fig. 5c). The Rossby waves dissipate while traveling and when they reach the African coast they warm the SSTs. This can already be seen in the December SSTs. The speed of propagation of the Rossby waves is $0.5 \mathrm{~ms}^{-1}$, somewhat slower than the theoretical speed for the first baroclinic Rossby mode between $4^{\circ}-2^{\circ}$ latitude of $0.7 \mathrm{~ms}^{-1}$ (Yamagata et al. 2004). The equatorial Kelvin wave takes less than a month to reach the Eastern IO boundary and deepens the thermocline there without affecting the SSTs much.

The precipitation (Fig. 5e) responds locally to the SST changes. The cooling over the Dome reduces the convection leading to a reduction in the total precipitation of significant amplitude in December, while over the warming region at the equator the first signs are visible of enhanced convection with increased precipitation in December.

This concludes the description of the forced phase of the simulation. We will continue to describe the further adjustments of the atmosphere-ocean system to the prescribed wind stress anomaly from January onwards during the unforced phase of the simulation. (b)

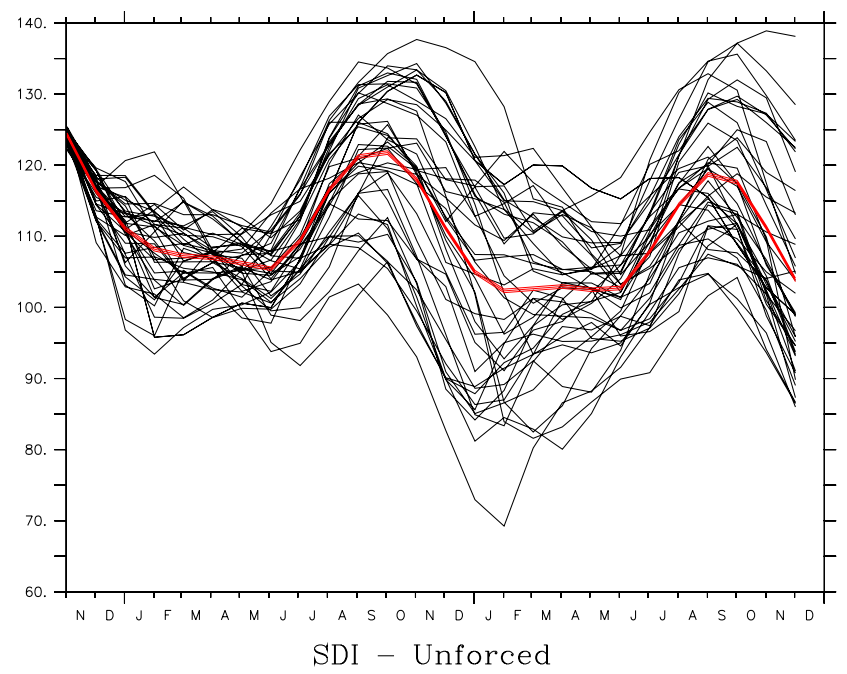

difference between both ensembles is the application of a prescribed windstress over the SD region in the forced ensemble during the first two months of the simulation. Units are meters of depth

\subsection{Unforced phase of the simulation}

We will separately discuss the adjustments along the equator, in the tropical IO south of the equator and the atmospheric response away from the equator.

\subsubsection{Equatorial adjustments}

We describe the equatorial ocean and atmosphere response that initiates from the Western IO basin and gradually extends to the East Pacific. We start from the SST and thermocline anomalies in the Western equatorial IO. Then continue with the subsequent changes over the Eastern equatorial IO, that are followed by adjustments in the warm pool region. The equatorial adjustments reach the East Pacific 5-6 months after the initiation of the SD event and beyond this time-scale the anomalies weaken as the system relaxes back to climatology.

In January the thermocline (Fig. 6) and SST (Fig. 7) adjustments reach their maximum amplitudes along the equator near the coast of Africa. The thermocline deepens up to $30 \mathrm{~m}$ when the Rossby waves reach the coast and cause a warming of the SSTs. The atmosphere dampens this warming, as the convection is strengthened in response to the warmer SSTs (see vertical pressure velocity changes in Fig. 8) with increased precipitation (Fig. 9) and cloudiness (not shown) leading to a reduction in solar radiation reaching the surface and a net cooling of the ocean by the surface heat fluxes (Fig. 10). The maximum warming of 
Fig. 5 Differences between the two ensemble means for November and December, the months with the prescribed windstress over the SD region for a curl of the wind stress in $10^{-7} \mathrm{Nm}^{-3}$, b vertical ocean velocities averaged between the longitudes $55^{\circ} \mathrm{E}-65^{\circ} \mathrm{E}$ in $\mathrm{ms}^{-1}$, c D20 in meters, $\mathbf{d}$ SSTs in ${ }^{\circ} C$, and $\mathbf{e}$ precipitation in mmday $^{-1}$. In all plots the contours represent areas exceeding the $98 \%$ level of significance, computed by a Student's t-test
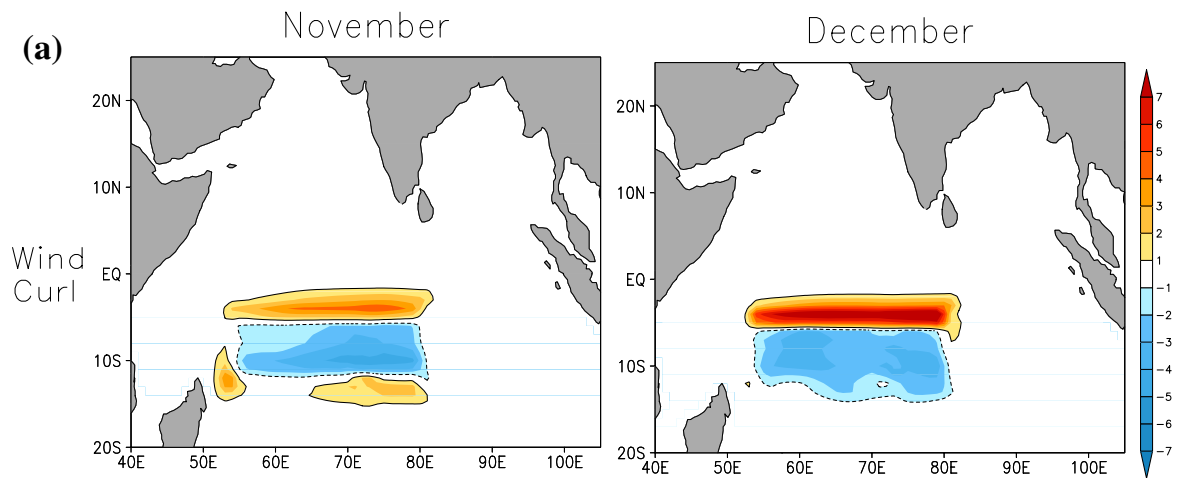

(b)
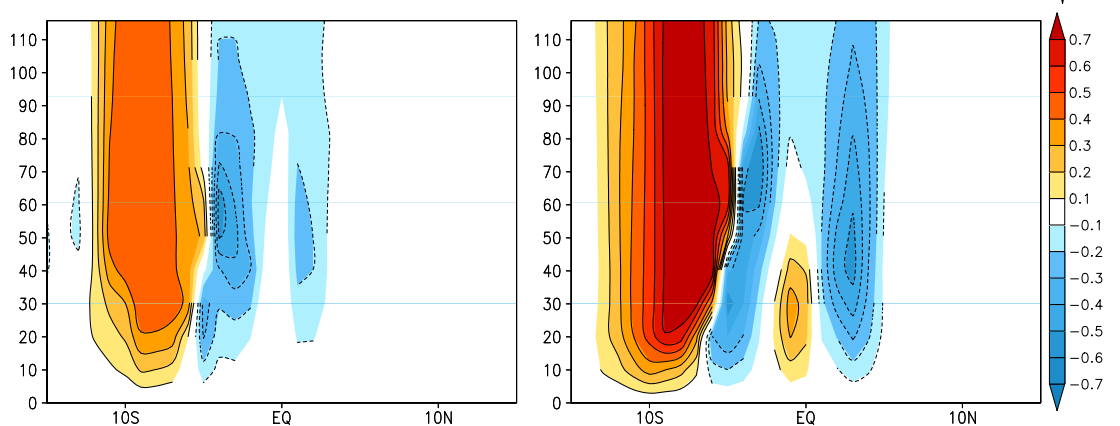

(c)
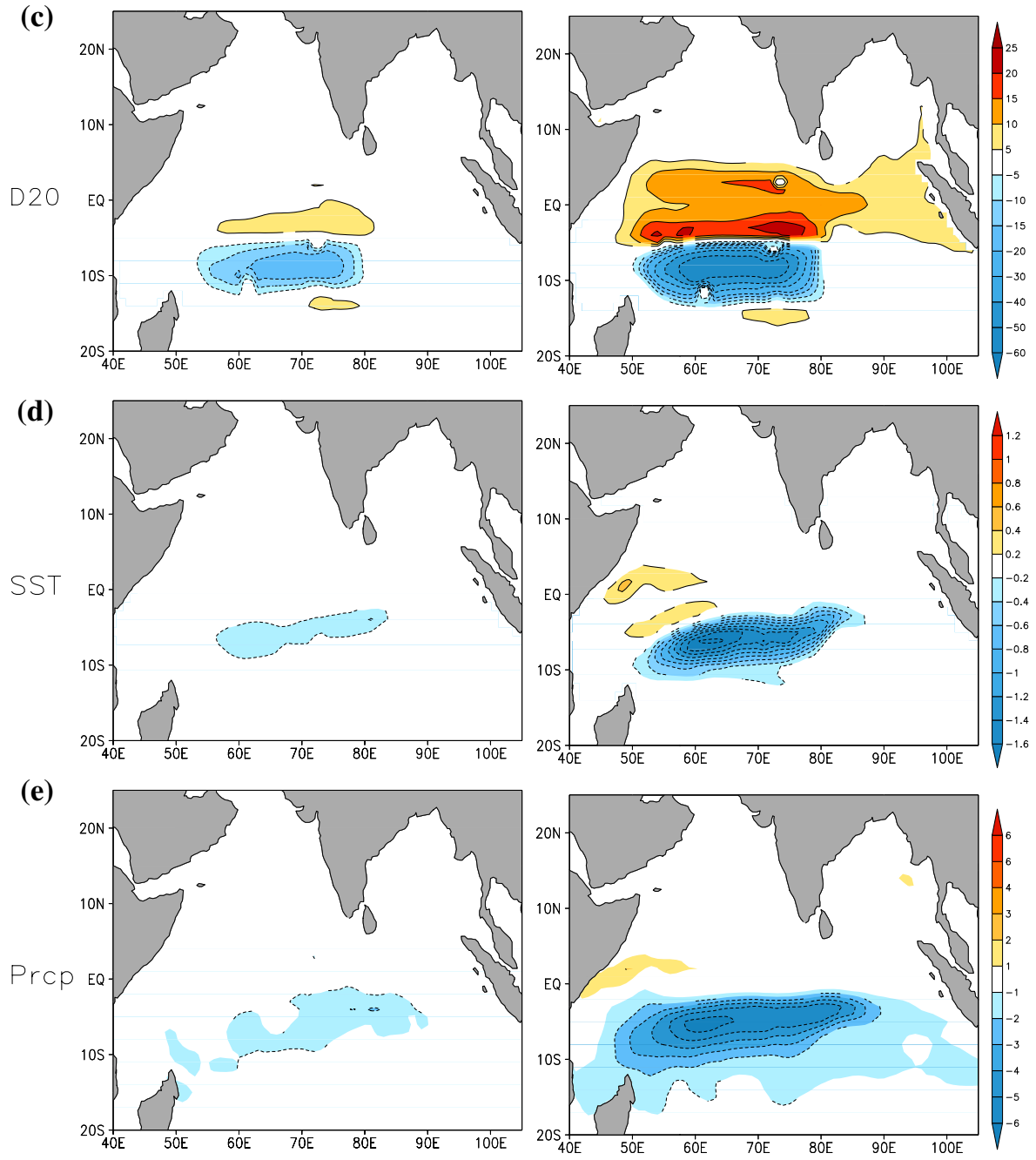
Fig. 6 Differences between the forced and the unforced ensemble for the depth of the $20^{\circ} \mathrm{C}$ isotherm for the months January to June. The units are in meters. The contours represent the areas exceeding the $98 \%$ level of significance
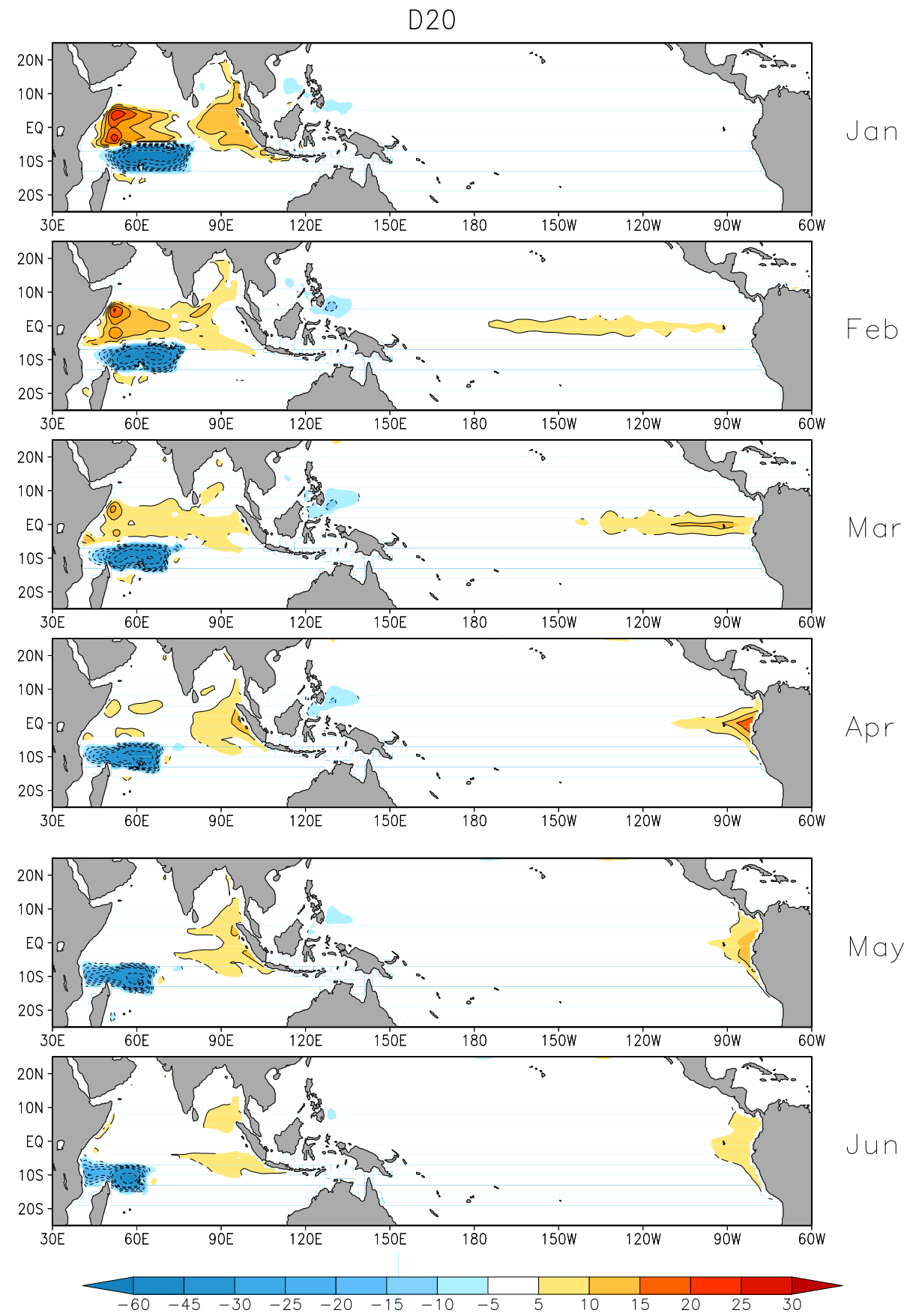

the SSTs is about $1{ }^{\circ} \mathrm{C}$, which corresponds to 1.5 times the standard deviation of January anomalies in the control simulation for this region.

When the Kelvin wave reaches Indonesia the thermocline deepens up to $15 \mathrm{~m}$ (Fig. 6). The SSTs do not respond significantly to this signal, since the the sensitivity of the SSTs to thermocline changes over the Eastern IO is not strong, as is apparent in the correlation plot in Fig. 1 and the magnitude of the thermocline change is not very large. Additionally any warming from below is locally damped by the surface fluxes in December (not shown) and January (Fig. 10) that tend to cool the SSTs over the region. The negative net surface heat fluxes over the Eastern IO and Indonesia are attributed to intensified winds in the area that lead to enhanced cooling by the turbulent heat fluxes.

The enhanced warming over the Western equatorial IO and cooling over the Eastern equatorial IO slows down the IO Walker circulation, as evident by the vertical velocity (Fig. 8) and surface windstress changes, (Fig. 11) with 
Fig. 7 Differences between the forced and the unforced ensemble for the SSTs for the months January to June. The units are ${ }^{\circ} \mathrm{C}$ and the contours represent areas exceeding the $98 \%$ level of significance
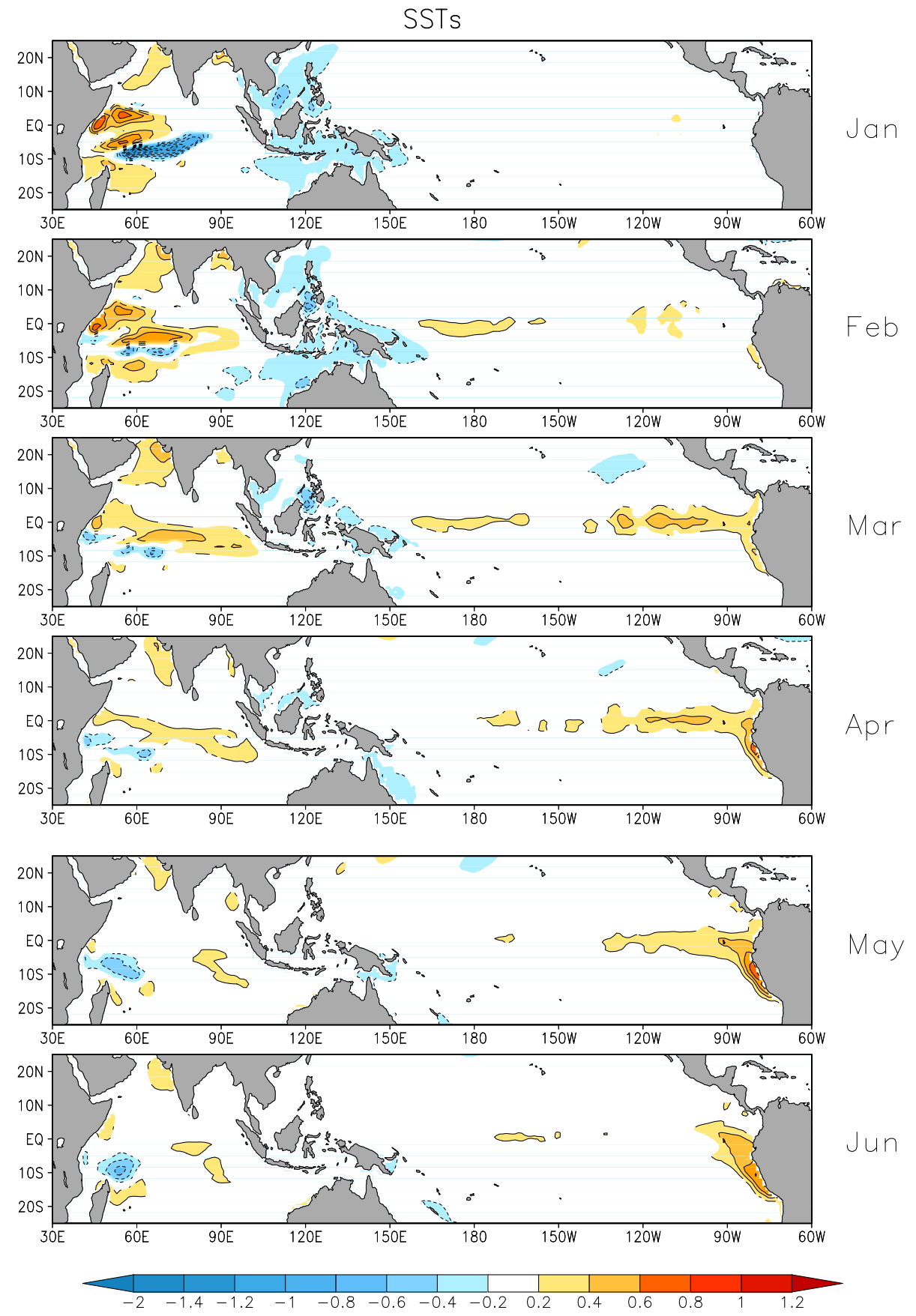

anomalous easterlies over and just South of the equator in the eastern Indian Ocean. In February, when the Walker circulation adjustments are most pronounced, the anomalous easterlies peak and cover the entire basin.

Due to the surface wind divergence over Indonesia in January, anomalous westerlies blow over the Western Pacific that shift the convective area of the warm pool eastward, around $170^{\circ} \mathrm{E}$, where the anomalous westerlies converge with the climatological easterlies. The shift is visible in the vertical velocity (Fig. 8) as well as in the precipitation change (Fig. 9).
In the ocean, the anomalous westerly wind stress over the Western Pacific sets off a downwelling equatorial Kelvin wave in January that moves eastward, shallowing the thermocline over the Western Pacific thereby enhancing the anomalous cooling and deepening the thermocline while passing over the Central and Eastern Pacific, inducing a surface warming. The wave reaches the eastern boundary in March and spreads the warming along the coast. The warming is maximum $0.7^{\circ} \mathrm{C}$ along the equator and reaches $1^{\circ} \mathrm{C}$ along the coast. The coastal warming is about half standard deviation of the local monthly climatology, and 
Fig. 8 Differences between the forced and the unforced ensemble for the vertical pressure velocity $\mathrm{W}$ along the equator for the months January to June. The units are $\mathrm{Pas}^{-1}$ and the contours represent the areas exceeding the $98 \%$ level of significance
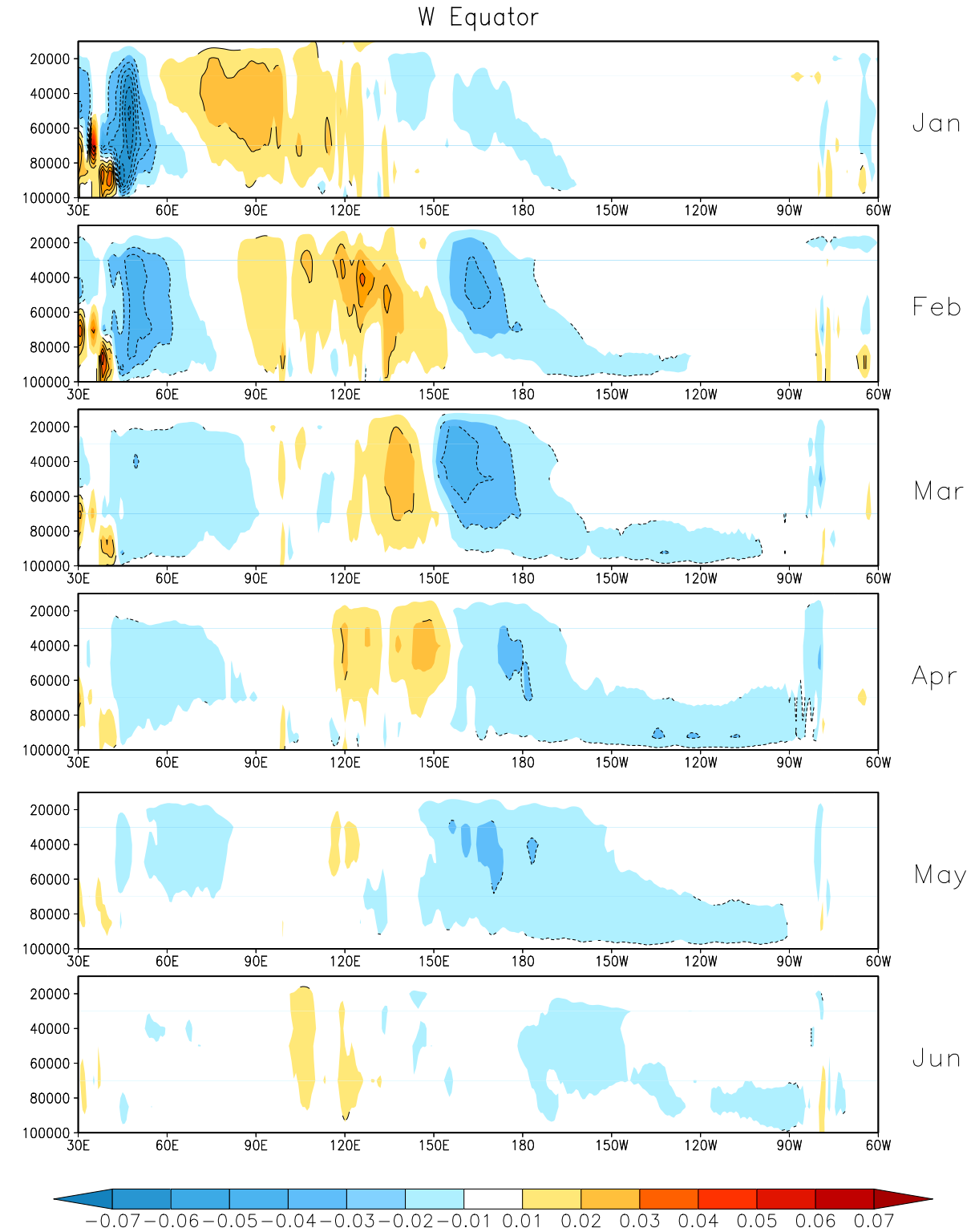

remains significant along the coast until July. The temporal evolution of the traveling wave and the induced SST anomalies is visible in the plots of the D20 (Fig. 6) and the SST adjustments (Fig. 7).

The atmosphere weakly responds to the warming of the SSTs with some enhanced convection and precipitation, but as seen in the vertical velocity changes (Fig. 8), the convection adjustment is only shallow and the precipitation increase is barely 1 mmday $^{-1}$ (Fig. 9). The induced eastwest pressure gradient is not strong enough to drive strong anomalous westerlies and trigger a Bjerknes feedback that could amplify the warming and create an ENSO-like response. In the subsequent months the atmosphere and ocean relax back to climatology.

This concludes the equatorial adjustments and we continue with the adjustments in the Southern IO.

\subsubsection{Adjustments in the Southern IO}

We start this section with a description of the SDI evolution and the response and feedback of the overlying atmosphere. Then the oceanic propagation of the signal is presented and the section is concluded with a discussion of the changes in the Intertropical Convergence Zone (ITCZ).

The temporal evolution of the adjustment of the thermocline depth in the SD region during the 26 months of simulation (Fig. 4) shows that after having reached a minimum depth in January of about $65 \mathrm{~m}$ (an anomaly of about two standard deviations), the Seychelles dome returns to climatological values within six months. Beyond July, the Seychelles dome behaves as in the unforced ensemble.

The relatively quick return to climatology is due to an atmospheric feedback. The wind stress curl adjustment in 
Fig. 9 Differences between the forced and the unforced the months January to June. The units are mmday ${ }^{-1}$ and the contours represent areas exceeding the $98 \%$ level of significance ensemble for precipitation for
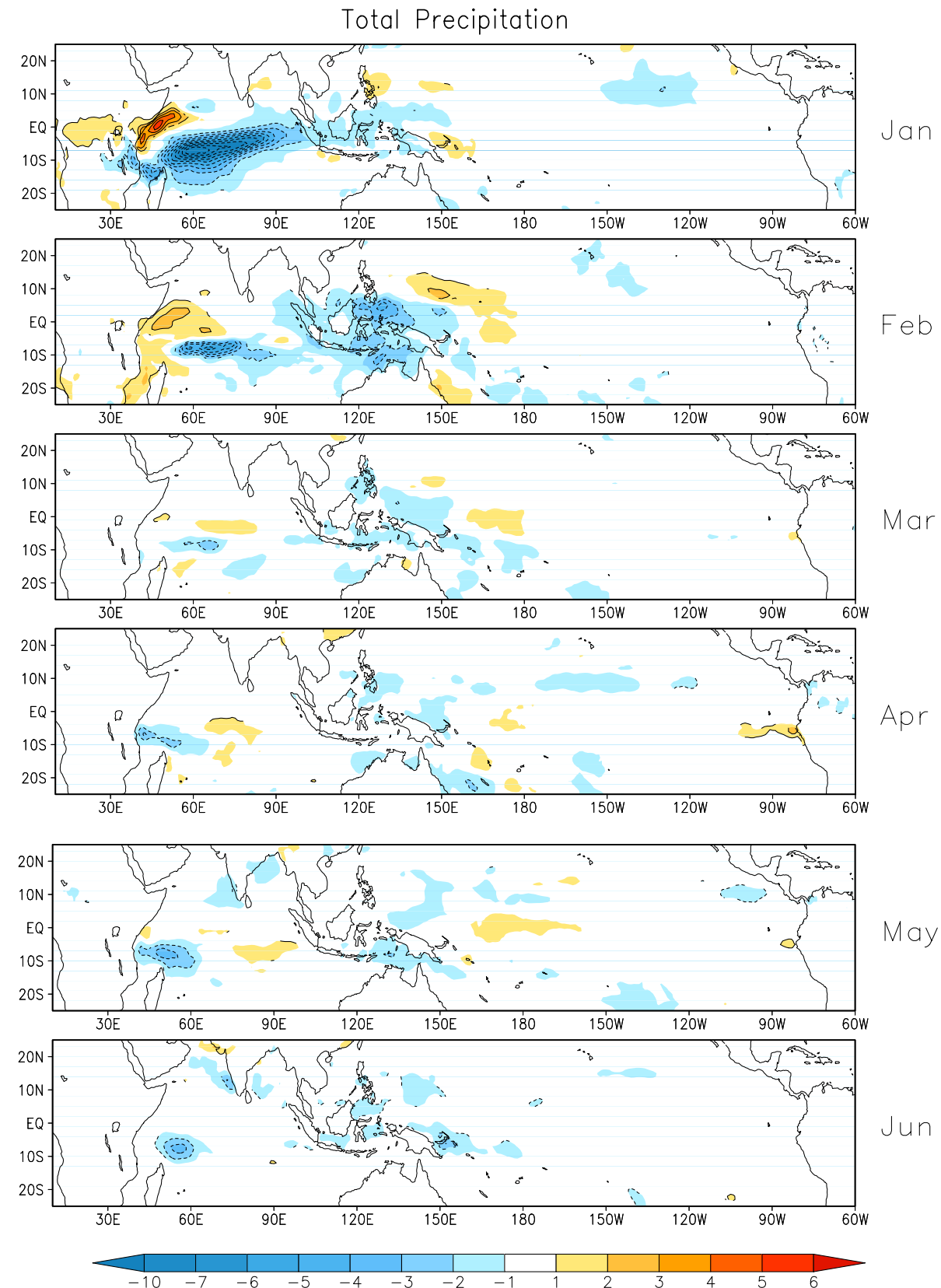

January and too a lesser degree in February (Fig. 12) has opposite sign with respect to the forced wind stress curl anomaly (Fig. 5a) leading to Ekman downwelling in the $\mathrm{SD}$ region and upwelling to the north, damping the forced anomalies.

The wind stress curl changes are part of the atmospheric adjustments to the cold SSTs in the SD region. The SSTs over the Dome follow the SDI anomalies and reach maximum cooling of about $2{ }^{\circ} \mathrm{C}$ in January, corresponding to two times the standard deviation locally for this month (Fig. 7).

The cold SSTs suppress convection in the region as evidenced by the pressure velocity changes averaged between $5-10^{\circ} S$ (Fig. 13) and a reduction of the total precipitation
(Fig. 9). The anomalous subsidence not only damps the cold SST anomaly by its associated wind stress curl and forced downwelling, it also adiabatically warms the air over the Dome and damps the forced cooling through the net surface heat fluxes (Fig. 10) that warm the ocean surface in the Dome region and to the north. Part of this warming is due to solar radiation as the reduced convection leads to reduced cloud cover in the region (not shown). The surface heat flux adjustments thus feed back negatively on the SD cooling and positively on the warming north of the SD region. By February the cold SST anomaly in the SD region is reduced by more than $50 \%$ while the warm region to the north has retained its amplitude. 
Fig. 10 Differences between the forced and the unforced ensemble for the net surface heat flux for the months January to April. The net surface heat fluxes are computed as the sum of the net solar and long-wave radiation and the sensible and latent heat flux. The units are $\mathrm{Wm}^{-2}$ and the contours represent areas exceeding the $98 \%$ level of significance

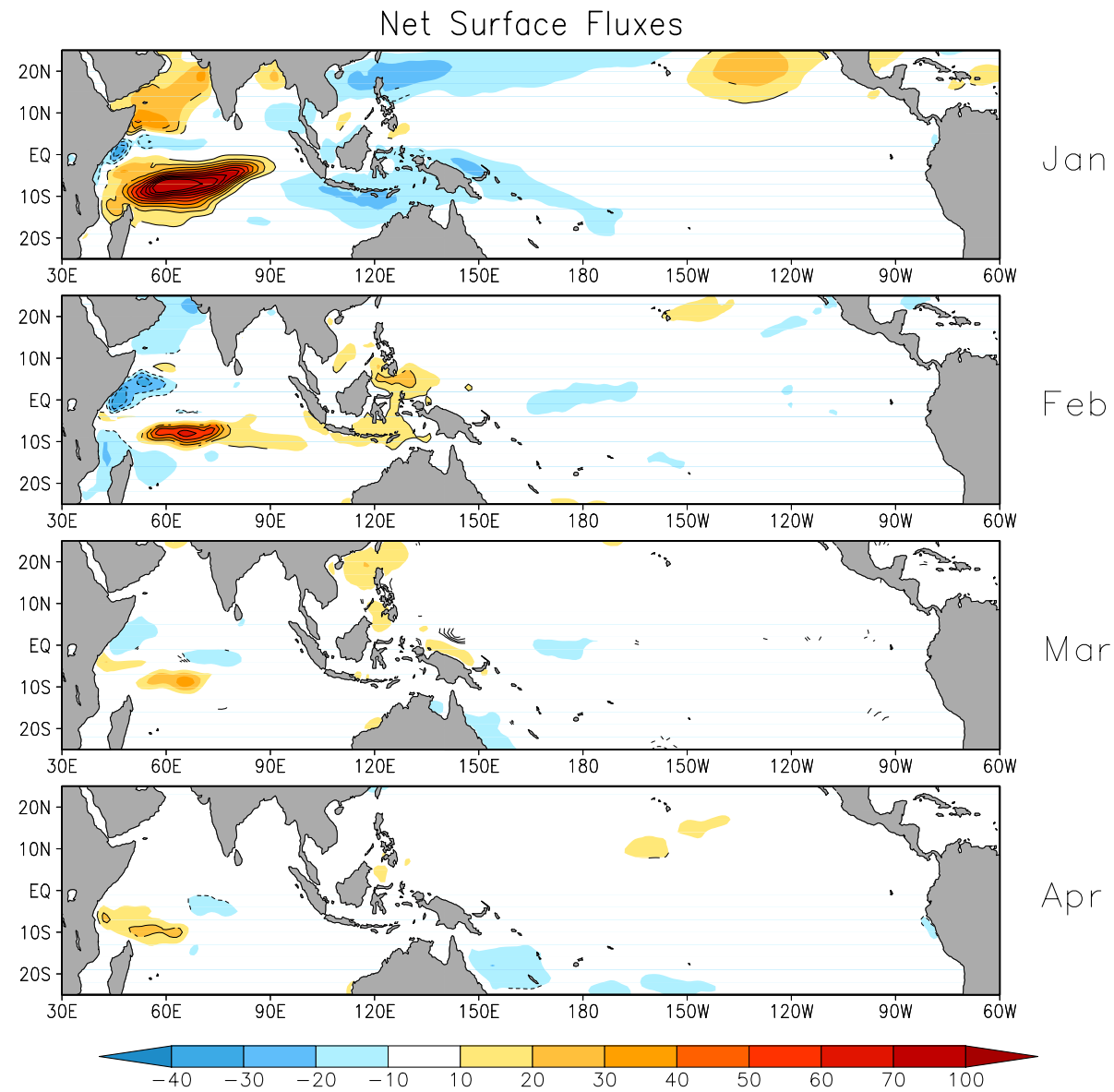

The warming to the north of the SD region spreads eastward in February and March (Fig. 7) and atmospheric convection is weakly enhanced between $70 \mathrm{E}$ and $90 \mathrm{E}$ during April and May with negative pressure velocities anomalies (Fig. 13), increased precipitation (Fig. 9) and cooling of the SSTs by the net surface heat fluxes (Fig. 10). These adjustments relax back to climatology in mid-summer.

The upward shift of the thermocline over the SD initiates an upwelling baroclinic Rossby wave that propagates westwards and dissipates. It reaches the African coast on average 8 months later, as seen in the Hovmöller diagram of the sea surface height (Fig. 14). The Rossby wave propagation is also clearly visible in the lat-lon plots of the SST and D20 adjustments (Figs. 7 and 6 respectively), where the center of the cold anomaly slowly moves to the west. The phase speed of the wave at $10^{\circ} \mathrm{S}$ is about $0.14 \mathrm{~ms}^{-1}$, slower than the theoretical speed of the first baroclinic mode of a free Rossby wave at this latitude for the Indian Ocean (Chelton et al. 1998; Yamagata et al. 2004). The slower propagation speed has been attributed to the coupling between the ocean and the atmosphere (White 2000) as the Rossby wave interacts with the surface winds, but could also be due to a different stratification in EC-Earth. Similar propagation speeds for this region were found by
Xie et al. (2002), using in-situ measurements and modelassimilated data sets, by Tozuka et al. (2010) using model simulations and others.

The combination of the cold SST anomalies over the SD region and the warm SST anomalies around the equator drive a northward shift of the ITCZ of about $4^{\circ}$ in the Central-Western IO that is apparent until March (Fig. 9). In January the northward shifts extends over Central Africa, causing a significant increase in the rainfall between $5^{\circ} \mathrm{S}$ and $5^{\circ} \mathrm{N}$ and and a decrease between $12^{\circ} \mathrm{S}$ and $5^{\circ} \mathrm{S}$.

\subsubsection{Remote adjustments through atmospheric Rossby waves}

Changes in tropical convection potentially affects extratropical weather patterns through excitation of large-scale, atmospheric Rossby waves (Hoskins and Karoly 1981; Branstator 1983; Hoskins and Ambrizzi 1993; Trenberth et al. 1998; Haarsma and Hazeleger 2007). The anomalous upper level winds accompanying the change in convection constitute a Rossby wave source (Sardeshmukh et al. 1987) and Rossby wave energy disperses away from the tropics, sometimes trapped by the atmospheric jets that can act as a Rossby wave guide (Branstator 2002). The strength 
Fig. 11 Differences between the forced and the unforced ensemble for the wind stress for the months January to June. The vectors show the wind direction and the amplitude of the wind stress is shaded in red colors. The units are in $\mathrm{Nm}^{-2}$ and the contours represent areas exceeding the $98 \%$ level of significance for the zonal wind stress difference
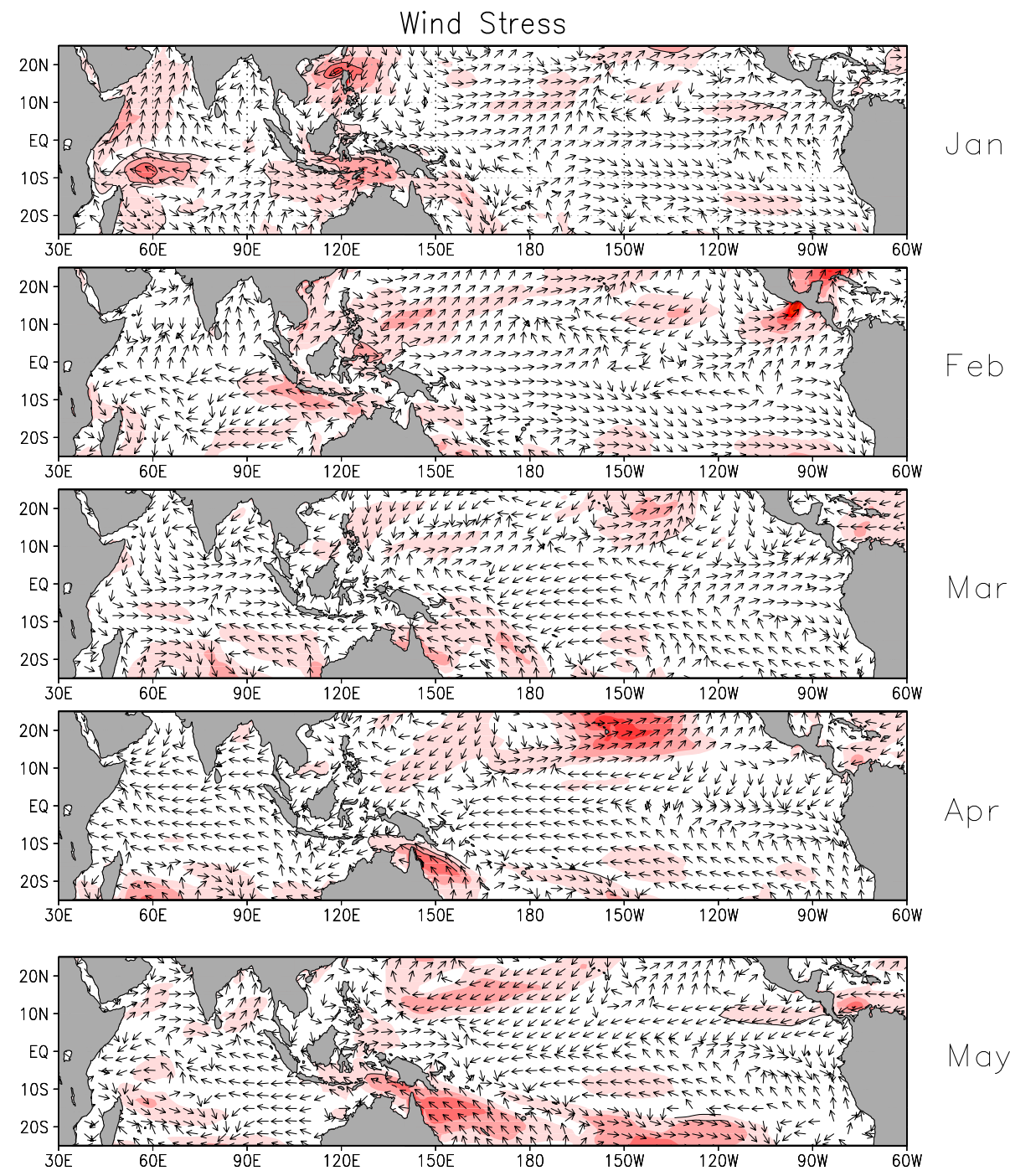

May

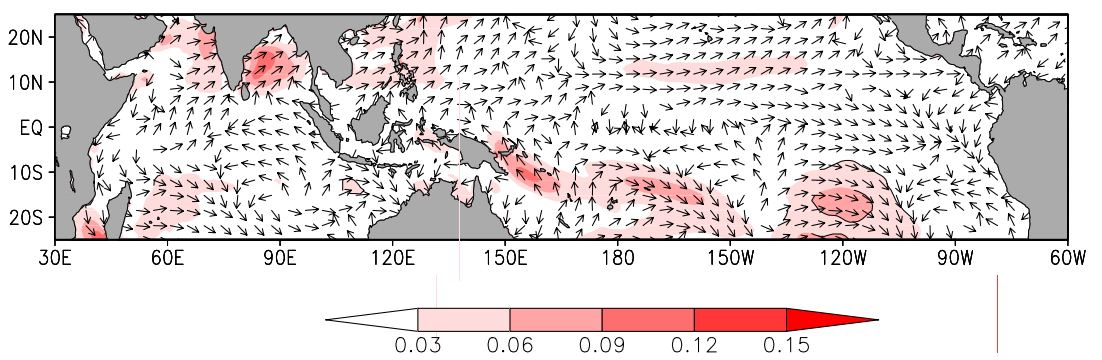

Jun of the waveguide response depends on the position of the Rossby wave source with respect to the jet and the width and strength of the jet itself (Manola et al. 2013), such that in the winter season, the waveguide response is generally strongest.

The waveguide response is most easily visualized by upper level meridional wind anomalies. Figure 15 shows the meridional wind anomalies at $200 \mathrm{hPa}$ on top of total wind contours to indicate the position of the jet stream. In January a strong response is observed over the north-western and north-eastern IO, were a significant Rossby wave source is present due to the strong convection anomalies. A wave-like response continues along the winter jet stream and crosses the Northern American continent. In February and March the strong response over the IO mitigates, as the convection anomalies reduce, but a stationary Rossby wave pattern is persistent along the northern hemisphere jet stream. In April the jets are going through the seasonal transition and are weak in both hemispheres, therefore the wave anomalies are less significant. The following two months the southern hemisphere jet gains strength and picks up the signal from the cold anomaly over the SD that 

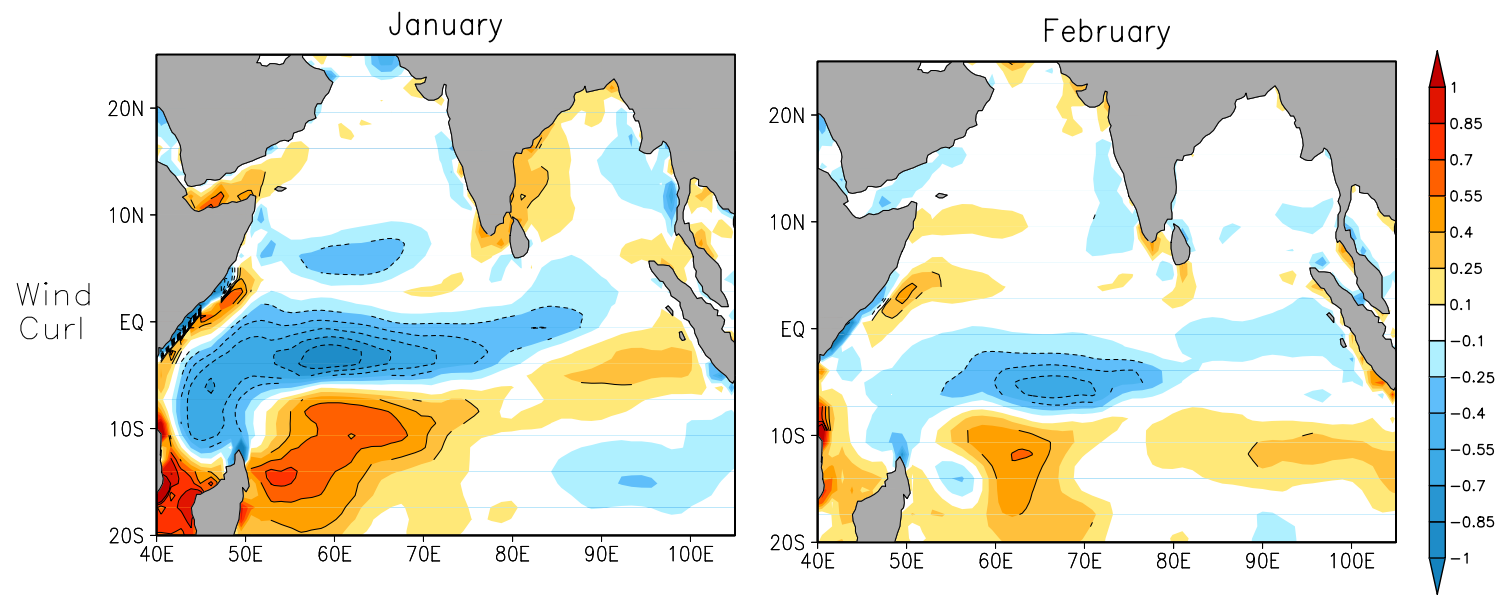

Fig. 12 Differences between the forced and unforced ensemble for the wind stress curl for the months of January and February. The contours represent the areas exceeding the $98 \%$ level of significance. The units are in $10^{-7} \mathrm{Nm}^{-3}$

Fig. 13 Differences between the forced and the unforced ensemble for the pressure velocity $\mathrm{W}$, averaged over the latitudes $5^{\circ} \mathrm{s}-10^{\circ} \mathrm{s}$ for the months of January to June. The units are in $\mathrm{Pas}^{-1}$. The contours represent the areas exceeding the $98 \%$ level of significance
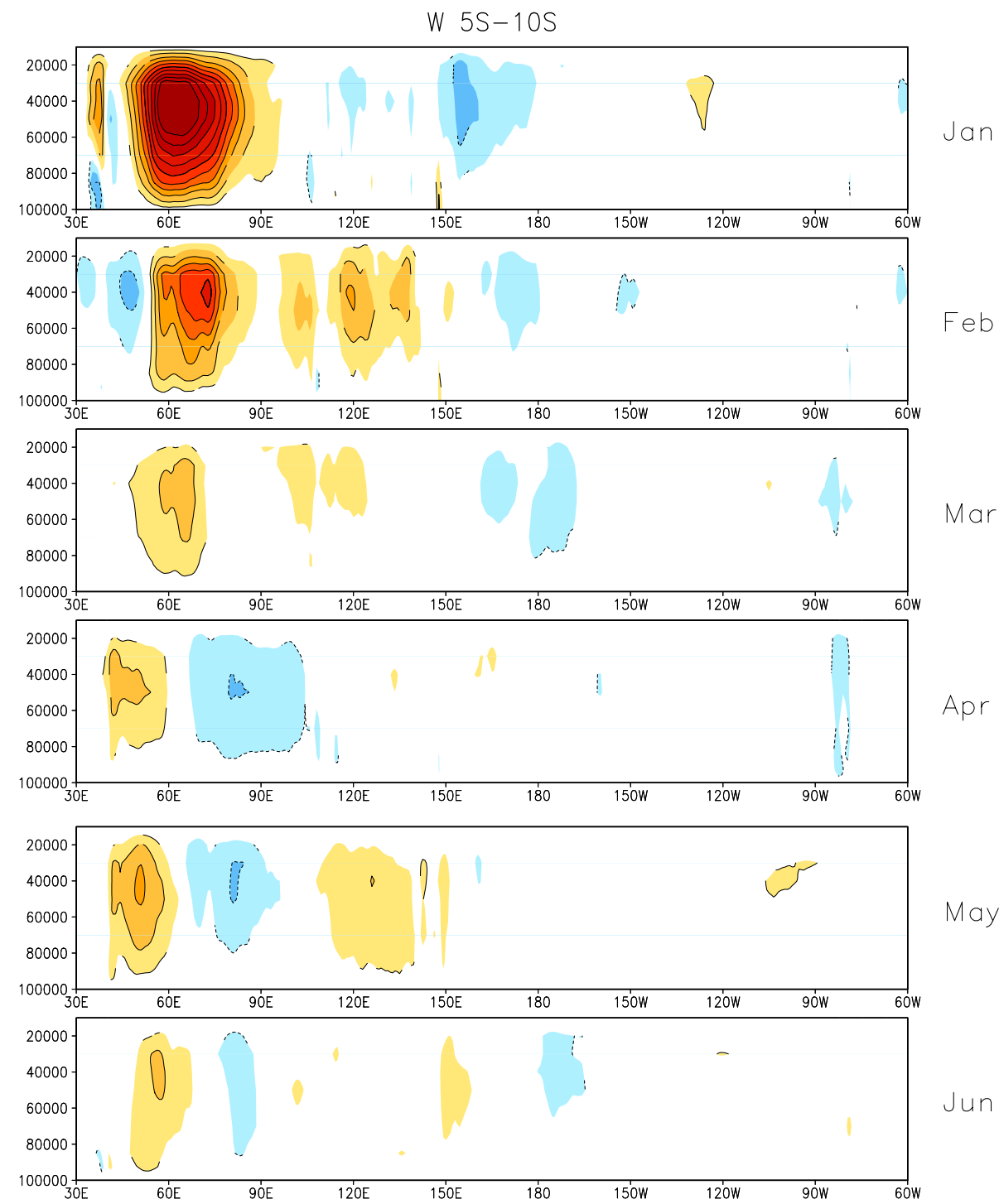

May 


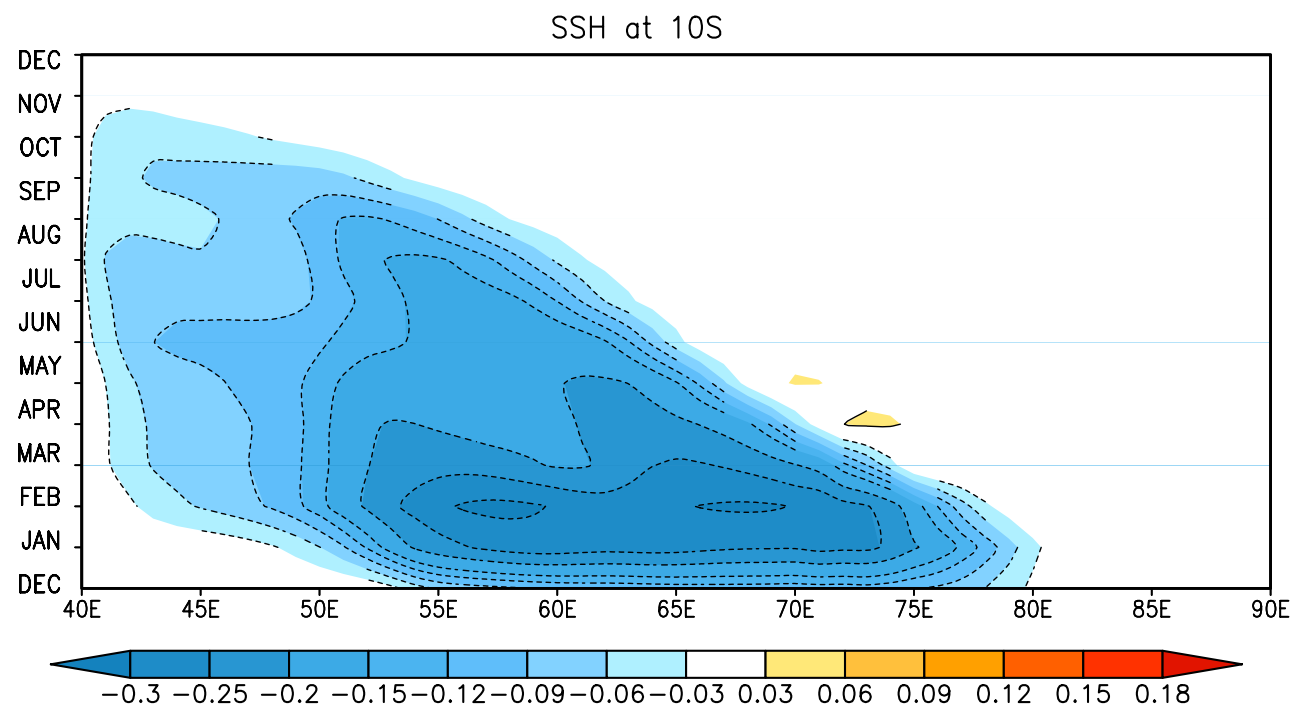

Fig. 14 A Hovmöller diagram of the sea surface height differences between the forced and the unforced ensemble during the first year at $10^{\circ} \mathrm{S}$. The units are in meters

is still significant, and a Rossby wave response is present in the southern hemisphere. In July the Rossby wave source is very weak as the convection adjustments have virtually relaxed back to climatology.

\section{Summary and discussion}

In this study we used the coupled atmosphere-ocean ECEarth model to study the response of the climate system to a shallow Seychelles Dome event in January. We found that the influence of the shallow event extends from the Indian Ocean into the East Pacific by a chain of events during the subsequent 6-8 months.

The forced upwelling in the SD region leads to a cold SST anomaly. In the subsequent months this anomaly propagates westwards in the form of a Rossby wave. The atmospheric convection is suppressed above the cold anomaly and the associated surface wind curl anomaly damps the upwelling Rossby wave. An equatorial adjustment north of the SD region manifests as a pair of downwelling westward moving Rossby waves and an eastward downwelling equatorial Kelvin wave. The Rossby waves warm the SSTs in the equatorial Western IO two months after the initiation of the Doming event and induce enhanced atmospheric convection. A Walker-type response follows with suppressed convection over the Indonesia-Warm Pool region. Here the SSTs cool through enhanced turbulent heat fluxes, resulting from stronger surface winds. The atmospheric convection is enhanced east of the warm pool region and a westerly wind anomaly sets off a downwelling Kelvin wave at the edge of the Pacific Warm Pool. The Kelvin wave arrives near the coast of Peru around 5 months after the initiation of the shallow SD event, resulting in a $0.5^{\circ} \mathrm{C}$ warming of the equatorial SSTs. A small weakening of the subsidence in the overlying atmosphere is simulated, but no indication of an unstable atmosphere-ocean interaction is found and the equatorial response is damped. This season is not favorable for unstable air-sea interactions. This is shown in Fig. 16, where the Nino 3.4 index is correlated with the zonal wind stress, indicating that the most favorable month for a strong air-sea coupling is November. We therefore suggest to repeat these type of experiments for different timings of the Doming events in the seasonal cycle. A Doming event starting in June could possibly trigger an ENSO in the Pacific, if conditions are favorable. A similar equatorial response to an IOD, although for a different season, is introduced in Izumo et al. (2010). They suggest that an IOD event may act as a precursor of an El Niño or a La Niña event: the east-west temperature anomalies during the IOD event can modify the Walker circulation. The zonal wind anomalies over the Pacific Ocean during the termination of the IOD in the autumn can force a Kelvin wave that propagates towards the eastern Pacific. The wave modulates the thermocline depth and the SSTs and through a Bjerknes feedback it can lead to the development of an El Niño or a La Niña event.

The combination of warm and cold SST anomalies at the equator and the SD drive a northward shift in the ITCZ that in January extends over the Central-East Africa influencing the precipitation. A shift of the ITCZ can also influence the onset of the monsoon period if it takes place in the right season. Annamalai et al. (2005a) found that a warming in the South-West IO in spring causes a delay in the 


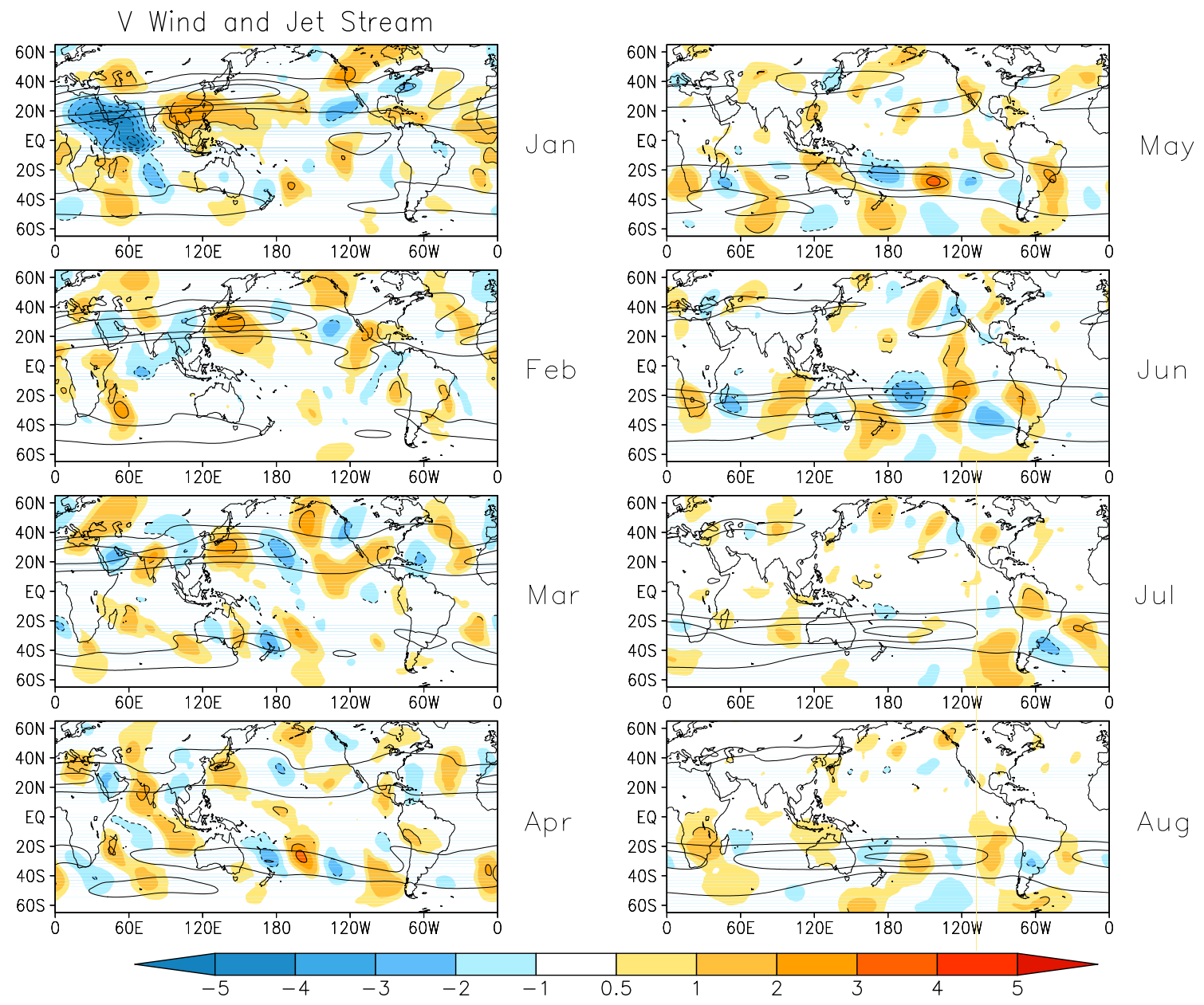

Fig. 15 In colors the anomalies between the forced and the unforced ensemble for the meridional wind $\mathrm{V}$ are plotted and in contours is the total wind from the forced ensemble from January to August. The units are $\mathrm{ms}^{-1}$ and the contours around the shades represent the areas

exceeding the $95 \%$ level of significance for the $\mathrm{V}$ anomalies. The first contour in the total wind is $20 \mathrm{~ms}^{-1}$ and the contour interval is $15 \mathrm{~ms}^{-1}$

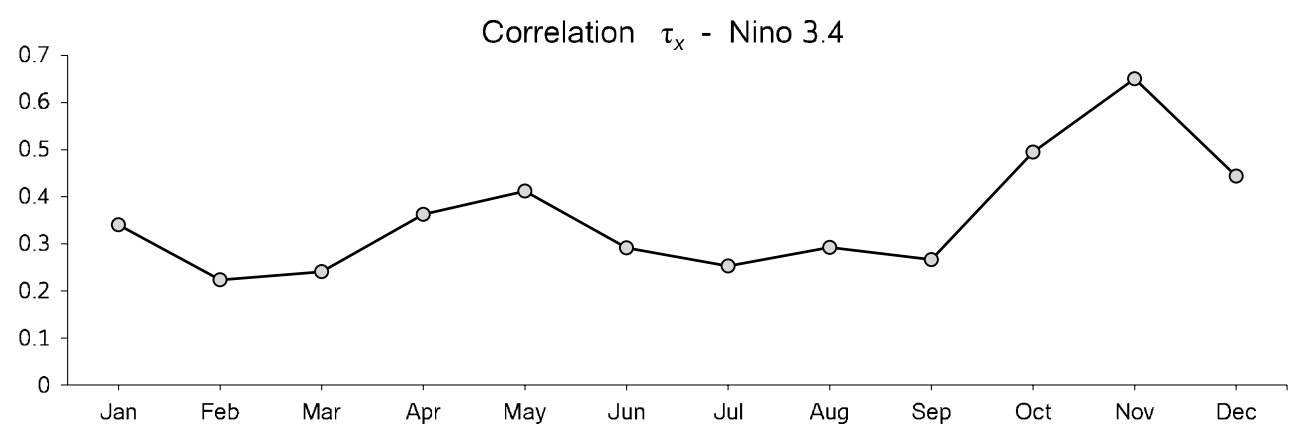

Fig. 16 The correlation between the Nino 3.4 index and zonal wind stress averaged over the same area from the 40 years of control run. The Nino 3.4 index is the averaged SST anomaly over $170^{\circ} \mathrm{W}-120^{\circ} \mathrm{W}$ and $5^{\circ} \mathrm{S}-5^{\circ} \mathrm{N}$

northward propagation of the ITCZ and the associated deep moist layer, provoking a delay of 6-7 days on the onset of the monsoon in June. Therefore it is possible that cold SD events, similar to those studied in this paper, taking place in April and May would force a premature initiation of the summer Indian monsoon.

In response to the atmospheric convection change in the equatorial IO, atmospheric Rossby waves are emanated and 
are visible in the winter hemisphere waveguides. As these responses depend on the atmospheric state, these would be different for different timings of Seychelles doming event in the seasonal cycle as well.

EC-Earth has a stronger coupling between the thermocline and the SSTs in the Western equatorial IO, as compared to observations. This probably makes the documented remote response to the SD event stronger than in nature. We therefore recommend to repeat these type of experiments with other models to assess the model dependency of these results and extend the observational analysis.

Acknowledgments The authors would like to thank Richard Bintanja and Camiel Severijns for their contribution to the model set up. This work is part of the research programme INATEX, which is (partly) financed by the Netherlands Organisation for Scientific Research (NWO).

Open Access This article is distributed under the terms of the Creative Commons Attribution License which permits any use, distribution, and reproduction in any medium, provided the original author(s) and the source are credited.

\section{References}

Annamalai H, Liu P, Xie SP (2005a) Southwest Indian Ocean SST variability: Its local effect and remote influence on Asian monsoons. J Clim 18:4150-4167

Annamalai H, Xie SP, McCreary JP, Murtugudde R (2005b) Impact of Indian Ocean sea surface temperature on developing El Niño. J Clim 18:302-319

Annamalai H, Okajima H, Watanabe M (2007) Possible impact of the Indian Ocean SST on the Northern Hemisphere circulation during El Niño. J Clim 20:3164-3189

Branstator G (2002) Circumglobal teleconnections, the jet stream waveguide, and the North Altantic Oscillation. J Clim 15:1893-1910

Branstator GW (1983) Horizontal energy propagation in a barotropic atmosphere with meridional and zonal structure. J Atmos Sci 40:1689-1708

Carton JA, Giese BS (2008) A reanalysis of ocean climate using simple ocean data assimilation (SODA). Mon Weather Rev 136:2999-3017

Chelton DB, Deszoeke RA, Schlax MG, Naggar KE, Siwertz N (1998) Geographical variability of the first baroclinic Rossby radius of deformation. J Phys Oceanogr 28(3):433-460

Chowdary JS, Gnanaseelan C, Xie S (2009) Westward propagation of barrier layer formation in the 2006-07 Rossby wave event over the tropical southwest Indian Ocean. Geophys Res Lett 36(4). doi:10.1029/2008GL036642

Duvel JP, Roca R, Vialard J (2004) Ocean mixed layer temperature variations induced by intraseasonal convective perturbations over the Indian Ocean. J Atmos Sci 61(9):1004-1023

Goddard L, Graham NE (1999) The importance of the Indian Ocean for simulating precipitation anomalies over eastern and southern Africa. J Geophys Res 104:19,099-19,116

Haarsma RJ, Hazeleger W (2007) Extra-tropical atmospheric response to Equatorial Atlantic cold tongue anomalies. J Clim 20:2076-2091

Hazeleger W, Wang X, Severijns C, Stefanescu S, Bintanja R (2012) EC-Earth V2. 2: description and validation of a new seamless earth system prediction model. Clim Dyn 39(11):2611-2629
Hermes JC, Reason CJC (2008) Annual cycle of the south Indian Ocean (Seychelles-Chagos) thermocline ridge in a regional oceanmodel. J Geophys Res 113(C04):035

Hoerling MP, Hurrell JW, Xu T, Bates GT, Phillips AS (2004) Twentieth century North Atlantic climate change. Part II: understanding the effect of Indian Ocean warming. Clim Dyn 23:391-405

Hoskins BJ, Ambrizzi T (1993) Rossby wave propagation on a realistic longitudinally varying flow. J Atmos Sci 50:1661-1671

Hoskins BJ, Karoly DJ (1981) The steady linear responses of a spherical atmosphere to thermal and orographic forcing. J Atmos Sci 38:1179-1196

Izumo T, de Boyer Montegut C, Luo JJ, Behera SK, Masson S, Yamagata $\mathrm{T}$ (2008) The role of the western Arabian Sea upwelling in Indian monsoon variability. J Clim 21:5603-5623

Izumo T, Vialard J, Lengaigne M, Behera S, Luo J, Cravatte S, Masson S, Yamagata T (2010) Influence of the state of the Indian Ocean Dipole on the following years El Nino. Nat Geosci 3(3):168-172

Jayakumar A, Gnanaseelan C (2012) Anomalous intraseasonal events in the thermocline ridge region of Southern Tropical Indian Ocean and their regional impacts. J Geophys Res: Oceans (19782012) 117.C3

Jayakumar A, Vialard J, Lengaigne M, McCreary JP, Gnanaseelan C, Kumar BP (2011) Processes controlling the surface temperature signature of the Madden-Julian Oscillation in the thermocline ridge of the Indian Ocean. Clim Dyn 37(11-12):2217-2234

Jochum M, Murtugudde R (2005) Internal variability of Indian Ocean SST. J Clim 18:3726-3738

Lloyd ID, Vecchi GA (2010) Submonthly Indian Ocean cooling events and their interaction with large-scale conditions. J Clim 23:700-716

Luffman JJ, Taschetto AS, England MH (2009) Global and regional climate response to late 20th century warming over the Indian Ocean. J Clim 23:1660-1676

Manola I, Selten F, de Vries H, Hazeleger W (2013) Waveguidability of idealized jets. J Geophys Res Atmos 118(18):10-432

Murtugudde R, Busalacchi AJ (1999) Interannual variability of the dynamics and thermodynamics of the tropical Indian Ocean. J Clim 12:2300-2326

Rao SA, Behera SK (2005) Subsurface influence on SST in the tropical Indian Ocean: structure and interannual variability. Dyn Atmos Oceans 39:103-139

Rayner NA, Parker DE, Horton EB, Folland CK, Alexander LV, Rowe DP, Kent EC, Kaplan A (2002) Global analyses of sea surface temperature, sea ice, and night marine air temperature since the late nineteenth century. J Geophys Res 108:D14

Rienecker MM, Suarez MJ, Gelaro R, Todling R, Bacmeister J, Liu E, MGB et al (2011) MERRA: NASA's modern-era retrospective analysis for research and applications. J Clim 24(14):3624-3648

Sardeshmukh PD, Prashant D, Hoskins BJ (1987) The generation of global rotational flow by steady idealized tropical divergence. $\mathrm{J}$ Atmos Sci 45:1228-1251

Schott FA, Xie SP, McCreary Jr JP (2009) Indian Ocean circulation and climate variability. Rev Geophys 47:RG1002

Swapna P, Krishnan R, Wallace JM (2013) Indian Ocean and monsoon coupled interactions in a warming environment. Clim Dyn 2(9-10):2439-2454

Tozuka T, Yokoi T, Yamagata T (2010) A modeling study of interannual variations of the Seychelles Dome. J Geophys Res 115(C04):005

Trenary L, Han W (2012) Intraseasonal-to-interannual variability of South Indian Ocean sea level and thermocline: remote versus local forcing. J Phys Oceanogr 42(4):602-627

Trenberth KE, Branstator GW, Karoly D, Kumar A, Lau NC, Ropelewski C (1998) Progress during TOGA in understanding and modeling global teleconnections associated with tropical sea surface temperatures. J Geophys Res 103:14,291-14,324 
Vecchi GA, Harrison DE (2004) Interannual Indian rainfall variability and Indian Ocean sea surface temperature anomalies. Am Geophys Union 147:247-260

Vialard J, Foltz G, McPhaden MJ, Duvel JP, de Boyer Montegut C (2008) Strong Indian Ocean sea surface temperature signals associated with the Madden Julian Oscillation in late 2007 and early 2008. Geophys Res Lett 35(19). doi:10.1029/2008GL035238

Vialard J, Duvel JP, McPhaden MJ, Bouruet-Aubertot P, Ward B, Key E, Bourras D et al (2009) Cirene: air-sea interactions in the Seychelles-Chagos thermocline ridge region. Bull Am Meteorol Soc 90(1):45-61

White WB (2000) Coupled Rossby waves in the Indian Ocean on interannual timescales. J Phys Oceanogr 30:2972-2988

Xie SP, Annamalai H, Schott FA, McCreary JP (2002) Structure and mechanisms of south Indian Ocean climate variability. J Clim $15: 867-878$
Yamagata T, Behera SK, Luo JJ, Masson S, Jury MR, Rao SA (2004) Coupled ocean-atmosphere variability in the tropical Indian Ocean. Earth's Clim. pp 189-211

Yang J, Liu Q, Liu Z, Wu L, Huang F (2009) Basin mode of Indian Ocean sea surface temperature and Northern Hemisphere circumglobal teleconnection. Geophys Res Lett 36(L19):705

Yokoi T, Tozuka T, Yamagata T (2008) Seasonal variation of the Seychelles Dome. J Clim 21:3740-3754

Zhou L, Murtugudde R, Jochum M (2008) Dynamics of the intraseasonal oscillations in the Indian Ocean South Equatorial Current. J Phys Ocean 38(1):121-132 